\section{AD 786}

Technical Report

\section{[R 815}

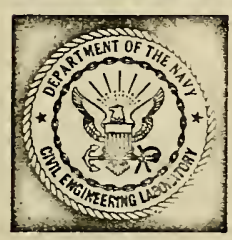

Sponsored by

NAVAL FACILITIES ENGINEERING COMMAND

August 1974

CIVIL ENGINEERING LABORATORY CIVIL ENGINEERING LABORATORY Woods Hole Oceanogiaphat
NAVAL CONSTRUCTION BATTALION CENTERNoods Hole, MA 02543
Robert G. Walden Woods Hole Oceanographic Institution
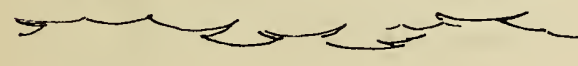

2

A SURVEY OF TECHNIQUES FOR THE ANALYSIS AND DESIGN OF SUBMERGED MOORING SYSTEMS

By N. D. Albertsen

Approved for publie release; distribution unlinited.

\title{
509
}





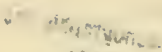

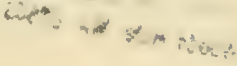


Unclasilicd

SECURITY CLASSIFICATIIHA NT THIS PAGE (HhEN Data Finiered

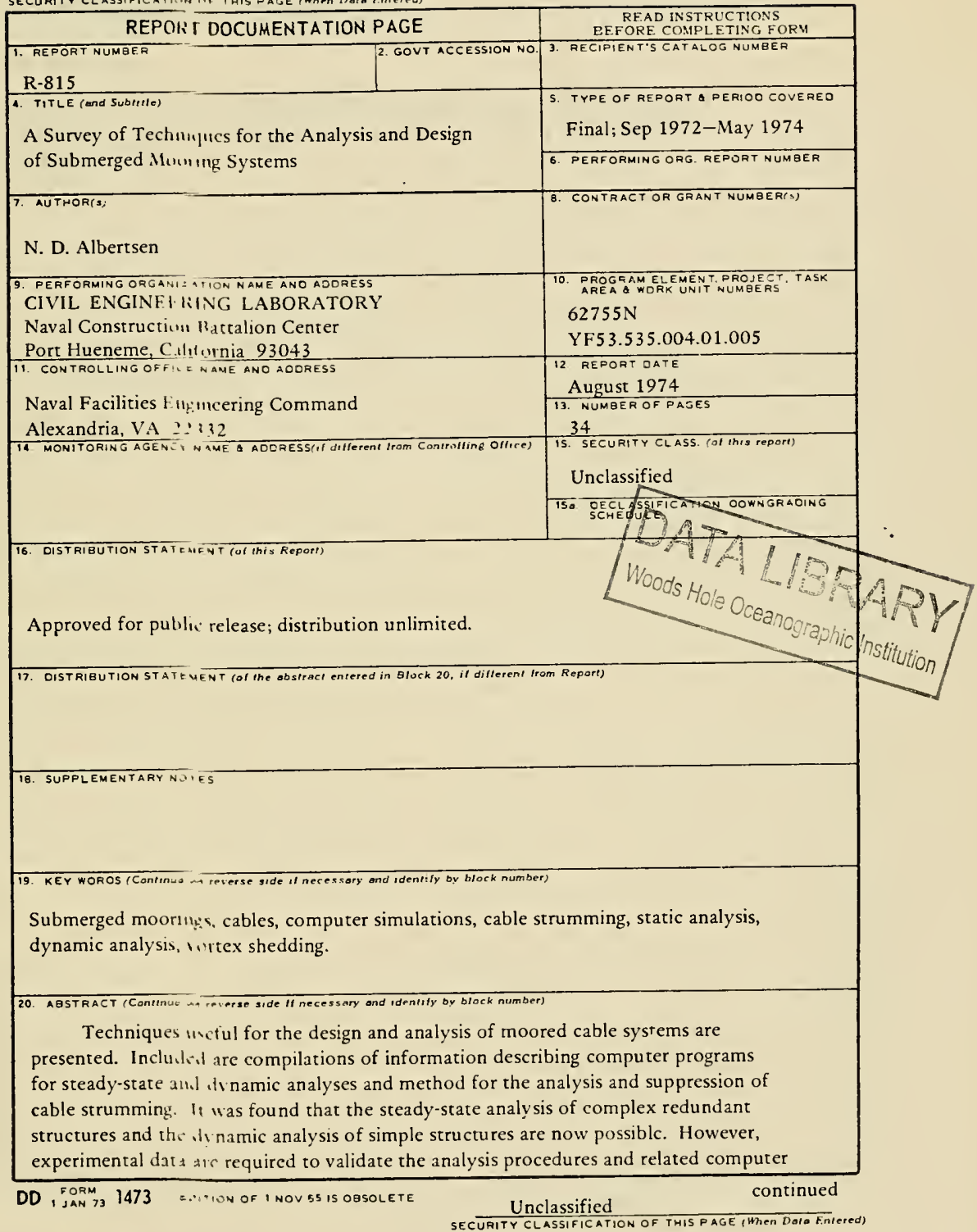

0030100401865 

20. Continued

programs. In addition, it was found that procedures still need to be developed to reliably predict, describe, and suppress cable strumming in long cables exposed to oceanic conditions. 



\section{INTRODUCTION}

This survey presents a summary of information for the analysis and design of one class of ocean structure, the moored cable system. The survey is divided into three broad analytical catcgories: (1) stcady-state analysis, (2) dynamic analysis, and (3) cable-strumming analysis and design considerations. The information is presented in a format which will help the engineer select a computer program, analytical model, or design tool which best fits his analysis or design needs.

Three previous surveys on the analysis of cable systems under hydrodynamic loading have summarized steady-state and dynamic models available to mid-1970 [1], summarized some of the new dynamic models to early 1973 [2], and reviewed the various mathematical techniques used in dynamic analysis [3]. The present survey attempts to update and complement these surveys to give a more complete picture of the state-of-the-art of steady-state and dynamic analyses and to present a summary of analytical techniques and design considerations for predicting and suppressing cable strumming.

Figure 1 presents the terminology used in this survey to describe the various mooring types. It is particularly noted that the terms used in Figure 1 to describe the moorings refer to the number of "legs" involved and not the number of buoys.

\section{STEADY-STATE ANALYSIS}

Table 1 presents computer programs for the steady-state (static) analysis of moored cable systems. These programs attempt to predict the distribution of stresses in the cables and the gcometry of moorings under the action of steady currents or other timeindependent forces. Information on how program authors can be contacted and source reference numbers are presented to enable the reader to obtain more details on the programs in which he is interested.
Terminology of Table 1

Each of the descriptive terms used in Table 1 are briefly discussed below.

Program Dimensionality. Programs for the analysis of moored cable systems may be one-, two-, or three-dimensional. Ilowever, most steady-state programs are either two- or three-dimensional so that the effects of nonaxial loadings (current forces, etc.) can be accounted for. Two-dimensional programs are useful for the analysis of single-point mooring systems in coplanar force fields. Three-dimensional programs are used in conjunction with multileg structures and nonplanar force fields. Elcven of the 27 entries in Table 1 are two-dimensional, 16 are three-dimensional.

Mooring Type. The terms used to define the mooring are given in Figure 1. Most of the programs in Table 1 are for the single-point mooring only: The program by R. A. Skop is a general one that can be applied to a variety of complex mooring configurations.

Cable Matcrial. A length of cable is compound if its physical or mechanical properties (area, modulus, etc.) vary along its length. A cable is extensible if it stretches under load. Both these cable characteristics are modeled by most of the programs in Table 1.

Current Profile Variation With Depth. Ocean currents at any specific point can vary in magnitude and direction with depth and timc. The effects of current variations with time are bcyond the capabilities of the static programs unless the changes occur very slowly so that the cime-dependent forces are very small. Gross errors can result if ocean-current regimes are not properly modeled by the computer program. The majority of the programs in Table 1 can model variations in current magnitude with depch; 13 programs can model current profiles that vary in magnitude and direction with depth.

Program Validation. None of the programs presented in Table 1 yield exact solutions because of 
assumptions associated with the structure and with hydrodynamic loading criteria and because of errors inherent in the computational techniques and machines. Therefore, to provide full confidence in a program it should be validated by comparing predicted results with precise experimental data. However, because little experimental data exists to validate programs, only a few of the programs for the simple mooring types have been validated.

Assumptions. The assumptions vary from program to program but basically center on the method used to model the structure and on the simplifications used in the calculation and application of the hydrodynamic loading forces.

Remarks. A brief summary of program characteristics and capabilities are presented, and the availability of program listings is indicated.

\section{Survey Results}

All the programs presented in Table 1 are operational. It should be mentioned that some of the dynamic programs use a steady-state program to establish a starting point for dynamic analysis. The entries in Table 1 based on Reference 16 by Patton and on References 37 and 38 by Goodman and Sargent are examples of static programs which are extracted from a dynamic program.

\section{DYNAMIC ANALYSIS}

In this section computer programs for the dynamic analysis of moored cable systems are presented. These programs try to simulate the dy namic response of various moored structures under rhe action of time-dependent forces other than those produced by vortex shedding. Table 2 presents the programs and attempts to update and complement the surveys presented in References 1 through 3.

\section{Terminology of Table 2}

Each of the descriptive terms found in Table 2 are briefly discussed below.
Program Dimensionality. As with the steady-state programs, the dynamic programs may be one-, two- or three-dimensional. The two programs in Table 2 that are one-dimensional examine the behavior of a mooring system along the cable axis. The remaining programs are concerned with tensions and displacement of the system in a plane or in space. The authors of several of the two-dimensional programs feel that extension to the third dimension would not require large amounts of reprogramming. To simulate the ocean environment, particularly near the surface, three-dimensional analysis is many times a necessity because of nonplanar wind, wave, and current forces.

Mooring Type. Again the reader is referred to Figure 1 for definitions of the terms used to describe mooring-system types. Most of the programs listed in Table 2 are for the single-point mooring.

Solution Method. A variety of solution methods are used in the dynamic programs. Reference 3 gives an excellent summary of the methods with their merits and demerits.

System Exeitation. The environmental factors which produce the dynamic system response are summarized here. The excitation sources are related to wave, wind, or current.

System Damping. The forces generated by mooring systems which oppose the dynamic response of the systems are called damping forces. Damping is generally hydrodynamic- or cable-rclated but may be assumed to be a function of the geometry or mass of the system. An excellent presentation of the Voight and Maxwell linear-damping models for eables is given in Reference to.

Properties of Cables. The assumptions associated with the cables are summarized here. in most cases all forces and mass are assumed to be concentrated at discrete points along the cable. The cables are assumed either to be completely flexible and elastic or to be made up of a series of springs or rigid segments interconnected with springs.

Status of Program. Information on whether the program is operational or proprietary is given. 

Remarks. A brief description of the program is given along with information concerning assumptions, computer-time requirements, and where a program listing may be found.

\section{Survey Results}

It is evident, after surveying the literature on moored-cable-system analysis in general and dynamic-cable analysis in particular, that two major deficiencies exist. First, experimental data to validate the programs are lacking; without this data, the precision and reliability of the programs are in doubt and, thus, the programs are of limited usefulness. Second, the dynamic programs must be generalized and streamlined so that complex, three-dimensional, moored structures can be analyzed using reasonable amounts of computer time.

\section{CABLE-STRUMMING ANALYSIS AND DESIGN CONSIDERATIONS}

When a cable is exposed to crossflow and the resulting Reynold's number lies between 90 and approximately $1 \times 10^{6}$ vortices spring from the sides of the cable, producing a fluctuating fluid pressure. The resulting forces cause the cable to vibrate in a plane normal to the directional fluid flow. This transverse vibration is cable strumming (sec References 42 , 69,70 , and 71 for descriptions of vortex-shedding, cable strumming phenomenon). Cable strumming in moored-cable systems produces cable fatigue, high acoustic noise levels, and increased drag. These factors all work to the detriment of the mooring and can cause failure or unacceptable performance. Thus, reliable methods for predicting when cable strumming will occur and ways to suppress strumming must be developed.

One way to predict and describe the cablestrumming phenomenon would be to solve the timedependent Navicr-Srokes equations for the threedimensional separated flow that is characteristic of cable strumming. Unfortunately, such a solution at this time is not possible because the strumming phenomenon still needs to be better understood. What is required is some "tool" that permits reliable prediction and description of cable strumming with- out being dependent on a complete numerical solution to the Navier-Stokes equations.

Below, information is presented to aid in the analysis and design of moored-cable systems that may be subjected to cable strumming.

\section{Mathematical Oscillator Models}

The oscillator models, presented in Table 3, attempt to duplicate the experimentally observed behavior of cables and other bluff bodies in crossflow. None of the models given in Table 3 is capable of predicting or describing cable strumming, but these models form a basc of information that, with further development, may result in a predictive tool.

\section{Flow Field Models}

Table + presents the flow field models which attempt to describe the flow fields near bluff bodies in crossflow. Advanced versions of these models may directly result in predictive and descriptive information for cable strumming; or they may produce new insight into the strumming phenomenon that, in turn, can be applied to the development of predictive or descriptive tools.

\section{Cable-Strumming Design Considerations}

This section presents currently available information pertaining to strumming prediction, increascd drag due to strumming, and strumming suppression. Though this design information yields only rough approximations, it will show a design engineer how to determine if strumming is probable, what can be done to estimate the resultant increase in drag for short smooth cables, and what methods are available to eliminate strumming.

Strumming Prediction. Experimental studies have shown that flexible cylinders and cables are induced to vibrate by vortex shedding at frequencies approximated by the String Equation $[103,104]$. The string equation for vibration in water is:

$$
f_{n}=(n / 2 L)\left(T / M_{c}\right)^{1 / 2}
$$



where $f_{n}=$ natural frequency $(\mathrm{Hz})$

$$
\begin{aligned}
\mathbf{n}= & \text { mode number }(1,2,3 \ldots) \\
\mathbf{L}= & \text { cable length }(\mathrm{ft}) \\
\mathbf{T}= & \text { cable tension }(\mathrm{Ib}) \\
\mathbf{M}_{\mathrm{c}}= & \text { virtual mass of cable }(\text { slug/ft) } \\
= & \text { mass of cable }+ \text { mass of } \\
& \text { equivalent volume of water }
\end{aligned}
$$

It has also been shown that the approximate frequency of vortex shedding from relatively short* cylinders and cables perpendicular to flow may be characterized by the Strouhal Equation $[103,104]$. The Strouhal relation is

$$
\mathrm{f}_{\mathrm{s}}=\mathrm{SV_{ \textrm {o } }} / \mathrm{d}
$$

where $f_{s}=$ Strouhal frequency $(\mathrm{Hz})$

$$
\begin{aligned}
\mathbf{S}= & \text { Strouhal number } \cong 0.2 \text { when } \\
& 2 \times 10^{2}<\mathrm{R}<1 \times 10^{5} \\
\mathbf{v}_{\mathbf{0}}= & \text { free stream velocity }(\mathrm{ft} / \mathrm{sec}) \\
\mathbf{d}= & \text { diameter of cable }(\mathrm{ft}) \\
\mathbf{R}= & \text { Reynolds Number }
\end{aligned}
$$

When the cable is inclined to the flow by an acute angle $\theta$ between the free stream and the cable, then the Strouhal relation is:

$$
\mathbf{f}_{\mathrm{s}} \cong\left(\mathrm{SV} \mathrm{v}_{\mathrm{o}} \sin \theta\right) / \mathrm{d}
$$

When the Strouhal frequency is found to be nearly the same as the natural frequency of the cable, the maximum vibration amplitude (for example, the worst strumming) occurs. The first step in investigating a cable segment for its propensity to strumming is to assign preliminary design values to the parameters in the string and Strouhal equations and then to determine if the resulting frequencies are nearly the same. If the frequencics are close, largeamplitude cable strumming may occur; if the frequencies are not close for scveral mode numbers, vibrations, if present, will probably be of small amplitude.

Increased Drag Due to Strumming. The following equation has been developed to predict the maximum drag coefficient (values for $C_{D}$ when $f_{s} \cong f_{n}$ ) that can be expected in short sections of a strumming, smooth, circular cable $[103,104]$ :

$$
C_{D_{s}}=C_{D}\left[1+10\left(d^{2} / M_{c}\right)^{2}\right]
$$

$$
\text { where } \begin{aligned}
C_{\mathbf{D}_{\mathrm{S}}}= & \begin{array}{l}
\text { drag coefficient for strumming } \\
\text { cable }
\end{array} \\
\mathbf{C}_{\mathrm{D}}= & \text { drag coefficient for stationary } \\
& \text { cable } \\
\mathrm{d}= & \text { cable diameter }(\mathrm{ft}) \\
\mathbf{M}_{\mathbf{c}}= & \text { virtual mass of cable }\left(\text { slug } / \mathrm{ft}^{3}\right)
\end{aligned}
$$

Equation 4 has been verified for small-diameter ( 0.057 in. $<d<0.140$ in.) smooth cables of mass per unit length from $1.16 \times 10^{-4}$ to $9.3 \times 10^{-4} \mathrm{slug} / \mathrm{ft}$ over a range of Reynolds numbers from 300 to 1,300 . No verification of the equation has been made for stranded cables.

Strumming Suppression. If strumming must be reduced or eliminated in a cable, changes can be made to the cable system so that the natural frequency and Strouhal frequency are much different or a cable fairing can be added to disrupt the vortex-shedding process. Figure 2 shows how four cable fairings compare in terms of strumning drag coefficient and strumming force over a range of Reynolds numbers. In Table 5, several arditional fairings are described and performance characteristics listed. It should be noted that for some fairings the drag cocfficient is increased over that of a bare cable even though strumming force or vibration amplitude is reduced.

To summarizc, analy'sis and design procedures to predict, describe, and suppress strumming in long cables under oceanic conditions are not possible. Today's procedures consist of comparing the natural frequency of a cable (Equation 1) with the Strouhal frequency for the cable in flow (Equations 2 or 3 ) to detcrmine if strumming is likely. If strumming is predicted on this basis, changes are made to the system or some fairing is added to the cable.

\footnotetext{
- A shor cable is one that does not exhihit large variations in normal velocity component due to cither streaming (bending' of the cable or nonuniform current profiles.
} 



\section{CONCLUSIONS AND RECOMMENDATIONS}

1. The steady-state analysis of complicated, multileg, redundant, submerged mooring systems is now possible.

2. The dynamic analysis of simple mooring systems, such as the single-point mooring and the bi-mooring is now possible.

3. Precise validation data for the steady-state and dynamic programs are needed to quantify the errors associated with the various techniques and to help select correct hydrodynamic loading criteria and added mass and damping coefficicnts used in the computer programs.

4. Analysis and design procedures need to be developed to reliably predict, describe, and suppress strumming in long cables in an ocean environment.

5. Experimental data are needed to aid in the development of a reliable tool to predict and describe cable strumming and in the development of practical strumming suppressors.

\section{REFERENCES}

1. M. J. Casarella and M. Parsons. "Cable systems under hydrodynamic loading," Marine Technology Society Journal, vol. 4, no. 4, July/Aug. 1970, pp. 27-44.

2. Hydrospace-Challenger, Inc. HCI TR 44500001 : An inventory of current mathematical models of scientific data-gathering moors, by D. B. Dillon. Rockville, Md., Feb. 1973.

3. Cathodic University of America, Report 73-1: A survey of analytical methods for dynamic simulation of cable-body systems, by Y. I. Choo and M. J. Casarclla. Washington, D. C., Mar. 1973.

4. Naval Rescarch Laboratory. Report 7296: The analysis of internally redundant structural cable arrays, by R. A. Skop and G. J. O'llara. Washington, D. C., Sep. 1971.

5. R. A. Skop and G. J. O'llara. "The method of imaginary reactions - a new technique for analyzing structural cable systems," Marine Technology Socicty Journal, vol. 4, no. 1, Jan/Feb. 1970, pp. 21-30.
6. R. A. Skop, "The method of imaginary reactions: applications to N-point moors," Preprints of the Sixth Annual Conference, June/July 1970, vol. 1. Washington, D. C., Marine Technology Society, 1970 , pp. 1-22.

7. Naval Research Laboratory. NRL Report 6894 : The static configuration of a tri-moored subsurface, buoy-cable array acted on by current-induced forces, by R. A. Skop and R. E. Kaplan. Washington, D. C. 14 May 1969.

8._ NRL Report 7640: A Fortran IV program for computing the static deflections of structural arrays, by R. A. Skop and J. Mark. Washington, D. C., Aug. 1973.

9. Woods Hole Oceanographic Institution. Report WHOl-73-85: Computer simulation of a tripod mooring for design and prediction, by N. N. Panicker. Woods Hole, Mass., Nov. 1973.

10. Bell Telephone Laboratories. Technical Report No. 14. The analysis of mooring systems and rigid body dynamics for suspended structures, by J. M. Gormally. Whippany, N. J., Dec. 1966.

11. Massachusetts Institute of Technology, Instrumentation Laboratory. Report E-2321: A stress and stability analysis of the pilot project oceanic telescope, by H. F. Little. Cambridge, Mass., Aug. 1968.

12. Naval Underwater Systems Center. Technical Memorandum No. SA2302-323-71: A finite element model of a submerged line array moored in uniform current fields, by J. D. Wilcox. New London, Conn., July 1971 .

13. J. W. Bendendender. "Three-dimensional boundary value problems for flexible cables," paper presented at Second Annual Offshore Technology Conference, Ilouston, Tex., April 1970. (OTC Paper No. 1281).

14. S. Bell, General Electric Co., personal communication: Outlinc of GE-RESD capability in static and dynamic analysis of mooring systems. Philadelphia, $\mathrm{Pa}$, Jan. 1973.

15. Woods [lole Oceanographic Institution. Report W11OI 68-79: Tension and geometry of single point moored surface buoy system, by W. D. Martin. Woods Ilole, Mass., Dec. 1968. 

16. Naval Underwater System Center. Technical Report 4331: The response of cable-moored axisymmetric buoys to ocean-wave excitation, by $\mathrm{K}$. $\mathrm{T}$. Patton. New London, Conn., June 1972.

17. D. B. Dillon. Hydrospace-Challenger Inc. cable programs, personal communication: HydrospaceChallenger Inc., Rockville, Md., J an. 1973.

18. S. M. Gay. "Computer analysis and design of undersea cable systems," Undersea Technology, vol. 9, no. 10, Oct. 1968, pp. 43-49.

19. Naval Ship Research and Dcvelopment Center. Report 3692: Effects of Nonplanar current profiles on the configuration of moored cable systems, by $\mathrm{H}$. T. Wang. Bethesda, Md., Oct. 1971.

20. H. T. Wang and B. L. Wester. "Current profiles which give rise to nonunique solutions of moored cable systems," paper presented at the Fourth Annual Offshore Technology Conference, Houston, Tex., May 1972. (OTC Paper No. 1538.)

21. John McChandless, Naval Air Development Center, Sonar Scnsor Division. Personal communication: Moor motion analysis at the Naval Air Development Center. Warminster, Pa., Dec. 1972.

22. D. Ilubbard, Naval Ordnance Laboratory, White Oak. Personal communication: . Ifoor motion analysis at the Naval Ordnance Laboratory. Silver Spring, Md., Jan. 1973.

23. M. Schreiber, Lockheed Missile and Space Co. Personal communication: Computer programs for the analysis of moored cable systems. Sunnyvale, Calif., Mar. 1973.

24. Lockheed Missile and Space Co. Unpublished document: Ocean systems structural analysis computer capabilities, by H. H. Eiriz. Sunnyvale, Calif., Feb. 1973.

25. Stanford University, Department of Petrolcum Engincering, School of Earth Sciences. Report No. : The design and analysis of a submerged, buoyant, anchored pipcline for transporting natural gas through the decp ocean, by G. II. Savage. Stanford, Calif., Aug. 1970. (NSF Contract No. Cill-61 and ONR Contract No. No0014-67-A-D 158-004)
26. University of New Hampshire, Engineering Design and Analysis Laboratory. Technical Report No. 104: Project Seaspider - Pacific; analysis of the motion of a tri-moored buoy with neutrally buoyant legs, by G. N. Sniffin and G. H. Savage. Durham, N. H., Feb. 1968.

27. John Mariano and A. Shashaty, Bell Laboratories, Cable Placing Group. Personal communication: Moor motion analysis at Bell Laboratories. Whippany, N. J., Dec. 1972.

28. Naval Underwater Systems Center. Technical Report 4379: Nondimensional steady-state cable configurations, by G. T. Griffin. New London, Conn., Aug. 1972.

29. Texas $A$ and $M$ University. COE Report No. 157: Three dimensional response of deep water mooring lines in steady current flow: mechanics of cable mooring systems, vol. I., by R. F. Dominguez and G. E. Owens. College Station, Tex., Dec. 1972.

30__ COE Report No. 158: Bi and quad cable arrays systems summary data report; Mechanics of cable mooring systems, vol. II, by R. F. Dominguez. College Station, Tcx., Feb. 1973.

31. COE Report No. 159: Parametric evaluations of bi and quad cablc array sy'stems; Mechanics of cable mooring systems, vol. III, by R. F. Dominguez and R. deCastongrene. College Station, Tex., Feb. 1973.

32 COE Report No. 160: A computer program for analyzing the steady-state response of bi and quad cable arrays; Mechanics of cable mooring systems, vol. IV, by R. F. Dominguez and N. M. Muska. College Station, Tex., Fcb. 1973.

33._ COE Report No. 161: The response of a tri-moored cable array with an included deformable cylindrical member; Mechanics of cable mooring systems, vol. V', by R. F. Dominguez and G. G. Greer. College Stution, Tex., Feb. 1973.

34._ COE Report No. 162: A computer program for analyzing the steady-state configuration of a trimoored array with included rigid and deformable members; Mechanics of cable mooring systems, vol. VI, by R. I. Dominguez, G. Ci. Greer, and A. C. Liau. College Station, Tex., Jan. 1973. 

35 COE Report No. 163: The steady-state behavior of a pyramid array system; Mechanics of cable mooring systems, vol. VII, by R. F. Dominguez, G. G. Greer and A. C. Liau. College Station, Tex., Mar. 1973.

36. R. F. Dominguez and R. W. Filmer. "Diserete parameter analysis as a practical means for solving mooring behavior problems," paper presented at the Third Annual offshore Technology Conference, Houston, Tex., Apr. 1971 (OTC Paper No. 1515).

37. National Data Buoy Center. Contract Report NDBCM 6113.1: Static and dynamic analysis of a moored buoy system, by T. R. Goodman, et al. Bay Saint Louis, Miss., Apr. 1972.

38 Contract Report NDBCM 6113.2: Computer program documentation report, buoy-cable dynamics program, by T. P. Sargent, A. I. Raff, and J. Bentson. Bay Saint Louis, Miss., Apr. 1972.

39. Naval Ship Research and Development Center. Report 2531: A Fortran IV program for the calculation of a flexible cable in a uniform stream, by Elizabeth Cuthill, Bethesda, Md., Feb. 1968.

40. University of Washington, Department of Civil Engincering, Division of Structures and Mechanics. Technical Report No. SM72: Frequency domain analysis for the tension in a taut mooring line, by $\mathrm{S}$. T. Hong. Scattle, Wash., July 1972.

41. L. H. Seidl. "On the dy'namics of a mooring line," Look Lab/Hawaii, vol. 2, no. 1, Jan. 197 1, pp. 11-22.

42. Naval Ordnance Laboratory, White Oak. TR-72-77: Cable strumming - some energy estimates for a moored mine system, by G. E. Ifudson. Silver Spring, Md., Jan. 1973.

43. W. Nerenstein and J. Nowatzki, Bendix Electrodynamic Corp. Personal communieation: Analysis of moored cable systems at Bendix Corp. Sylmar, Calif., Apr. 1973.

44. G. M. Research Laboratory. TR 65-79: The dynamics of simple deep-sea buoy moorings, by R. G. Paquette and B. E. Henderson. Santa Barbara, Calif., Nov. 1965.
45. C. S. Draper Laboratory. Report $R$ (in preparation): Mooring mechanies - a comprehensive computer study (Part I. Surface moorings; Part II. Subsurface moorings), by N. K. Chhabra. Cambridge, Mass., 1974.

46. P. Y. Chang and W. D. Pilkey. "Static and dynamie analysis of mooring lines," Journal of Hydronauties, vol. 7 , no. 1, Jan. 1973, pp. 29-34.

47 __ "The analysis of mooring lines," paper presented at Offshore Technology Conference, Ilouston, Tex., Apr. 1971 (OTC Paper No. 1502).

48. Woods Hole Oceanographie Institution. WHOI73-22: Computer program for the static analysis of single point moored surface and subsurface buoy systems, by H. O. Berteaux and N. K. Chhabra. Woods Hole, Mass., Mar. 1973.

49. D. J. Bennett, Bunker-Ramo, Electronic Systems Div., Government Systems Group. Personal communieation: Mooring analysis at Bunker-Ramo. Westlake Village, Calif., 20 July 1973.

50. Bunker-Ramo, Electronic Systems Division, Government Systems Group. Brochure No. 5240-338. VLAM-A multichannel acoustic measurement system, Westlake Village, Calif.

51. Swede Momson, G. M. Research Defense Laboratory. Personal communication: Cable analysis capabilities at G. M. Research Defense Laboratory. Santa Barbara, Calif., Jan. 1973.

52. H. C. Merchant and M. A. Kelf. "Nonlinear analysis of a submerged ocean buoy system," an abstract of a paper to be presented at Ocean 73, Seattle, Wash., Sept. 1973. (Abstract dated 19 Jan. 1973.)

53. M. A. Kelf. Non-linear analysis of submerged ocean buoy systems, M. S. thesis, University of Washington, Seattle, Wash., 1973.

54. N. T. Tsai. "Analysis of nonlinear transient motion of cables using bond graph method," Transactions of the ASME Journal of Engineering for Industry, May 1972.

55. N. T. Tsai, General Dynamics. Personal communication: Numerical models of mooring systems at General Dynamies. San Diego, Calif., Feb. 1973. 

56. Naval Ship Research and Development Center. NSRDC Report No. 3663: A two-degree-of-freedom model for the two-dimensional dynamic motions of suspended extensible cable systems, by H. T. Wang. Bethesda, Md., Oct. 1971.

57. Naval Air Systems Command. Report No. T72-AV-9602-V: Sonobuoy cable system analysis, by D. R. Sanders and W. L. Collier. Washington, D. C., Tracor Corp., Nov, 1972. (Contract N00019-72-C-0239).

58. R. A. McLauchlan, et al. "A dynamic analysis of moored and free-floating cablc systems," paper presented at the Fifth Annual Offshore Technology Conference, Houston, Tex., Apr. 1973. (OTC Paper No. 1742)

59. R. D. Taylor. An analytic model to predict the dynamic loading of a cable system in a linearly varying current profile, M. S. thesis, University of Texas, Austin, Tex., May 1973.

60. W. D. Iwan. "Dynamic response of suspended underwater systems," Journal of the Acoustical Society of America, vol. 51, no. 5, Part 2, 1972, pp. 1688-1696.

61. R. F. Dominguez and C: E. Smith, "Dynamic analysis of cable systems," Journal of the Structural Division, American Socicty of Civil Engineers, vol. 98, no. ST8, Aug. 1972, pp. 1817-1834.

62. B. W. Wilson and D. 11. Garbaccio. "Dynamics of ship anchor-lines in waves and current," Journal of the Watenways and I1arbors Division, ASCE, vol. 95, no. WW4, Nov. 1969, pp. 449-463.

63. Catholic University of America. Report 72-5: The dynamics of a ship moored by a cable sy'stem under sea state excitation, by E. E. Zarnick and M. J. Casarella. Washington, D. C., July 1972.

64. E. E. Zarnick. The dynamics of a ship moored by a cable system under sea state excitation, Ph.D. thesis, Catholic University of America. Washington, D. C., 1972.

65. Naval Civil Engineering Laboratory. Technical Note N-1053: Dynamic line force and oscillatory motion of a vessel being winched down in ocean two computer solutions, by C. L. Liu and J. A. Drelicharz. Port Ilucneme, Calif., Oct. 1969.
66. National Data Buoy Center. National Ocean Survey. Unnumbered report: A new technique for the solution of the equations of cable dynamics for the NDBC buoy-cable dynamics simulation, by A. Trampus. Rockville, Md., Dec. 1972.

67. R. Blumberg and C. D. Osborn. "Computer-aided design of submerged ocean buoy systems," paper presented at the First Annual Offshore Technolog: Conference. Houston, Tex., May 1969. (OTC Paper No. 1133)

68. C. S. Draper Laboratory. Report in preparation: Mooring dynamics experiment: determination of a verified dynamic model of the W.H.O.I. intermediate mooring, by N. Chhabra, et al. Cambridge, Mass., 1974.

69. J. R. Dale and R. A. Holler. "Spurious signals from cable-suspended sonar systems," Journal of Hydronautics, vol. 3, no. 2, Apr. 1969, pp. 83-87.

70. A. W. Marris. "A review on vortex streets, period wakes, and induced vibration phenomena," Journal of Basic Engineering, vol. 86, series D, no. 2, June 1964, pp. 135-196.

71. M. V. Morkovin. "Flow around circular cylinder - a kaleidoscope of challenging fluid phenomena," paper presented at American Society of Mechanical Engineers Symposium on Fully Separated Flow. Philadelphia, Pa., May 1964.

72. I. Dycr, Massachusetts Institutc of Technology: Personal communication: Dynamic response of deep mooring systems. Cambridge, Mass., June 1973.

73. I. L. Ver. "Power balance and statistical energy analysis," Proceedings of Intersociety Energy Conversion Engineering Conference, Boston, Mass., Society of Automotive Engincers, Inc., Aug. 1971, Pp. 1041-1047.

74. The Shock and Vibration Information Center. Monograph SVM-1: Random noise and vibration in space vehicles, by R. Il. Lyon. Superintendent of Documents, U.S. Government Printing Office, Washington, D. C., 1967.

75. R. 11. Lyon. "Statistical analysis of power injection and response in structures and rooms," The Journal of the Acoustical Society' of $\Lambda$ merica, vol. 45 , no. 3 , June 1967 , pp. 545-565. 

76. Y. Nakamura. "Vortex excitation of a circular cylinder treated as a binary flutter," Reports of Research Institute of $A$ pplied Nechanics, vol. XVIII, no. 59, 1969. (Kyushu University, Kushu, Japan,) pp. 217-234.

77. M. Funakawa. "Excitation mechanism of an elastically supported circular cylinder in a flowing fluid," Bulletin of Journal of Sociery of Mechanical Enginecrs, vol. 35 , no. 270, 1969, p. 303.

78. C. S. Draper Laboratory. Report in preparation: Lumped parameter representation of Karman vortex excitation, by D. G. Shepard. Cambridge, Mass., 1973.

79. G. D. Silvo. "Self-controlled vibration of a cylinder in fluid strcam," Journal of Engineering Mechanics Division, ASCE, vol. 95, no. EM2, Apr. 1969., pp. 347-361.

80. H. Halle. "Proposed analytical model for the cross-flow-induced vibrations of a circular cylinder," in Proceedings of Conference on Flow-Induced Vibrations on Reactor System Components, Argonne National Laboratory, Argonne, [ll., May 1970. (Argonne Laboratory Report ANL-7685).

81. R. T. Hartlen and I. G. Currie. "Lift oscillator model of vortex-induced vibration," Journal of Engineering Mechanics Division, ASCE, vol, 96, no. EM5, Oct. 1970, pp. 577-591.

82. I. G. Currie, R. T. Martlen, and W. W. Martin. "The response of circular cylinders to vortex shedding," paper presented at Symposium on Flowinduced Structural Vibration, Karlsruhe, Germany, Aug. 1972.

83. S. Kawamura. "A design criterion - wind loads of high steel stacks," Proceedings of the Third International Conference on Wind Effects on Buildings and Structures, Tokyo, Japan, 1971, pp. 707-716.

84. R. A. Skop and O. M. Griffin. "An hueristic model of determining flow induced vibrations of offshore structures," paper presented at the Fifth Annual Offshore Technology Conference, Ilouston, Tex., Apr. 1973. (OTC Paper No. 1843).
85. O. M. Griffin, R. A. Skop, and G. H. Koopman. "Measurement of the response of bluff cylinders to flow-induced vortex shedding," paper presented at the Fifth Annual Offshore Technology Conference, Houston, Tex., Apr. 1973. (OTC Paper No. 1814).

86. R. A. Skop and O. M. Griffin. "A model for the vortex-excited resonant response of bluff cylinders," Journal of Sound and Vibration, vol. 27, no. 2, . March 1973, pp. 225-233.

87. W. D. I wan and R. Belvins. Unpublished Manuscript. A model for vortex induced oscillation of structures, California Institute of Technology, Pasadena, Calif., Dec. 1973.

88. J. E. Fromm and F. H. Harlow. "Numerical solution of the problem of vortex street development," The Physics of Fluids, vol. 6, no. 7, July 1963, pp. 975-982.

89. D. C. Thoman and A. A. Szewczyk. "Timedependent viscous flow over a circular cyilinder," High-Speed Computing in Fluid Dynamics - The Physics of Fluids Supplement II, 1969, pp. I1-76 to I1-86.

90. T. Sarpkaya. "An analytical study of separated flow about circular cylinders," Journal of Basic Engineering, Dec. 1968, pp. 511-520.

91. T. Sarpkaya, Naval Postgraduate School. Personal communication: Flow field studics at the Naval Postgraduate School. Monterey, Calif., Mar. 1973.

92. A. D. K. Laird. "Eddy formation behind circular cylinders," Journal of the Hydraulics Division, ASCE, vol. 97, no. 11Y6, June 1971 , pp. 763-775.

93. A. D. K. Laird, University of California at Berkeley. Personal communication: Recent work on the vortex shedding phenomenon. Berkeley, Calif., Mar. 1973.

94. S. K. Jordan and J. E. Fromm. "Oscillatory drag lift and torque on a circular cylinder in a uniform flow," The Physics of Fluids, vol. 15, no. 3, Mar. 1973, pp. 371-376.

95. R. R. Clements. "An invisced model of twodimensional vortex shedding," Journal of Fluid Mechanics, vol. 57, part 2, 1973, pp. 321-337. 
96. Y. N. Chen. "Wake swing and vortex shedding in a cross flow past a single circular cylinder," paper presented at the Symposium on Flow-induced Structural Vibrations, Karlsruhe, Germany, IAHR and IUTAM, Aug. 1972.

97. J. S. Son and T. J. Hanratty. "Numerical solution for the flow around a cylinder at Reynolds numbers of 40,200, and 500," Journal of Fluid Mechanics, vol. 35, part 2, 1969, pp. 369-386.

98. 1. H. Gerrard. "The stability of unsteady axisymmetric incompressible pipe flow close to a piston, Part 1. Numerical analysis," Journal of Fluid Mechanics, vol. 50, part 1, 1971, pp. 625-644.

99 "The low frequency components of separated flows," paper presented at Symposium on Flow-induced Structural Vibrations, Karlsruhe, Germany, IAHR and IUTAM, Aug. 1972.

100. J. Shioiri. "Synchronization phenomenon in vortex shedding and its role in vortex induced oscillations of structures," in Proceedings of the Third International Conference on Wind Effects on Buildings and Structures, Tokyo, Japan, 1971.

101. North American Rockwell Corp. Report SD-68-996: Hydroelastic analysis of a circular cylinder, by B. H. Ujihara. Seal Beach, Calif., Dec. 1968. (Contract N0014-68-C-0223)

102. Report SD-69-558: Hydroelastic analysis of a circular cylinder/lift on bodies of revolution, by H. D. McLaughlin and B. H. Ujihara. Seal Beach, Calif, Dec. 1969. (Contract N00014-68-0223)

103. Naval Air Development Center. Report No. NADC-AE-6719: Determination of normal drag coefficients for flexible cables," by J. R. Dale. Warminster, Pa., June 1967.

104. Naval Air Development Center. Report No. NADC-AE-6731: Water drag effects of flow induced cable vibrations, by J. R. Dale, J. M. McChandless, and R. A. Holler. Warminster, Pa., Aug. 1967.

105. Naval Míne Defense Laboratory. Interim Report i-132: Drag and vibration of some wire ropes and fairings," by R. E. Kelly and C. N. Goff. Panama City, Florida, Sep. 1967.
106. Naval Ship Research and Development Center. Unpublished manuscript: Vortex induced vibration of bare and ribbon cables. Bethesda, Md., Sep. 1971. Robert Blevins.

107. A. Fabula, Naval Undenvater Center. Personal communication: Suppression of cable strumming in towed systems using helical strakes. San Diego, Calif., Feb. 1973. 


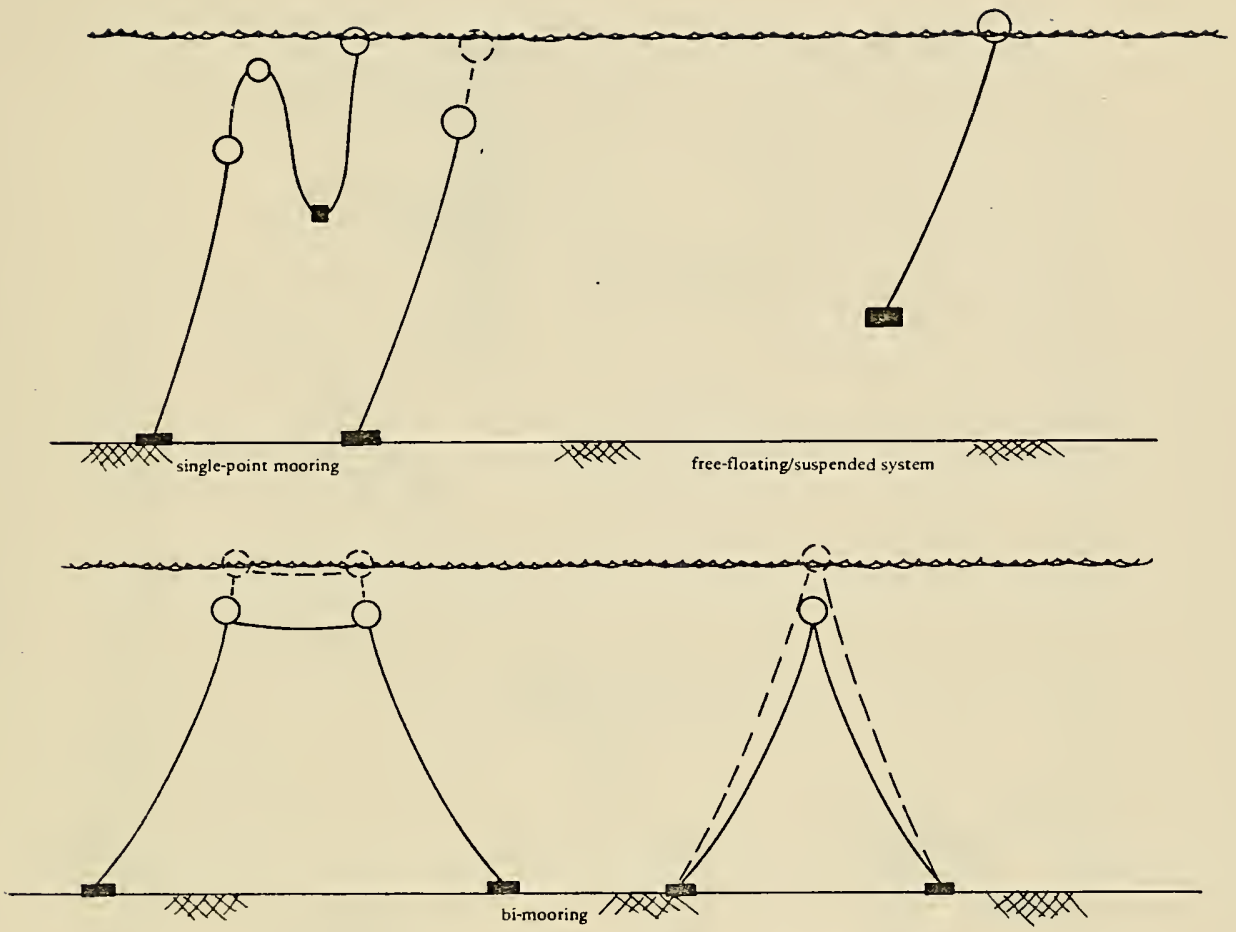

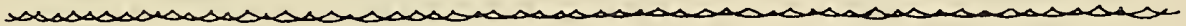

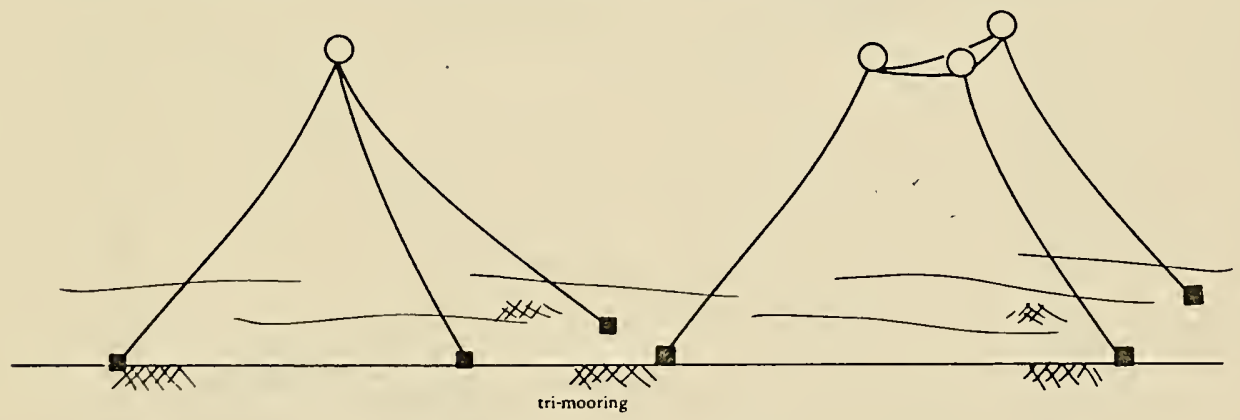

Note. A General Program is one which can simulate the behavior of the above moorings plus others of additionar complexity.

Figure 1. Mooring type terminology. 



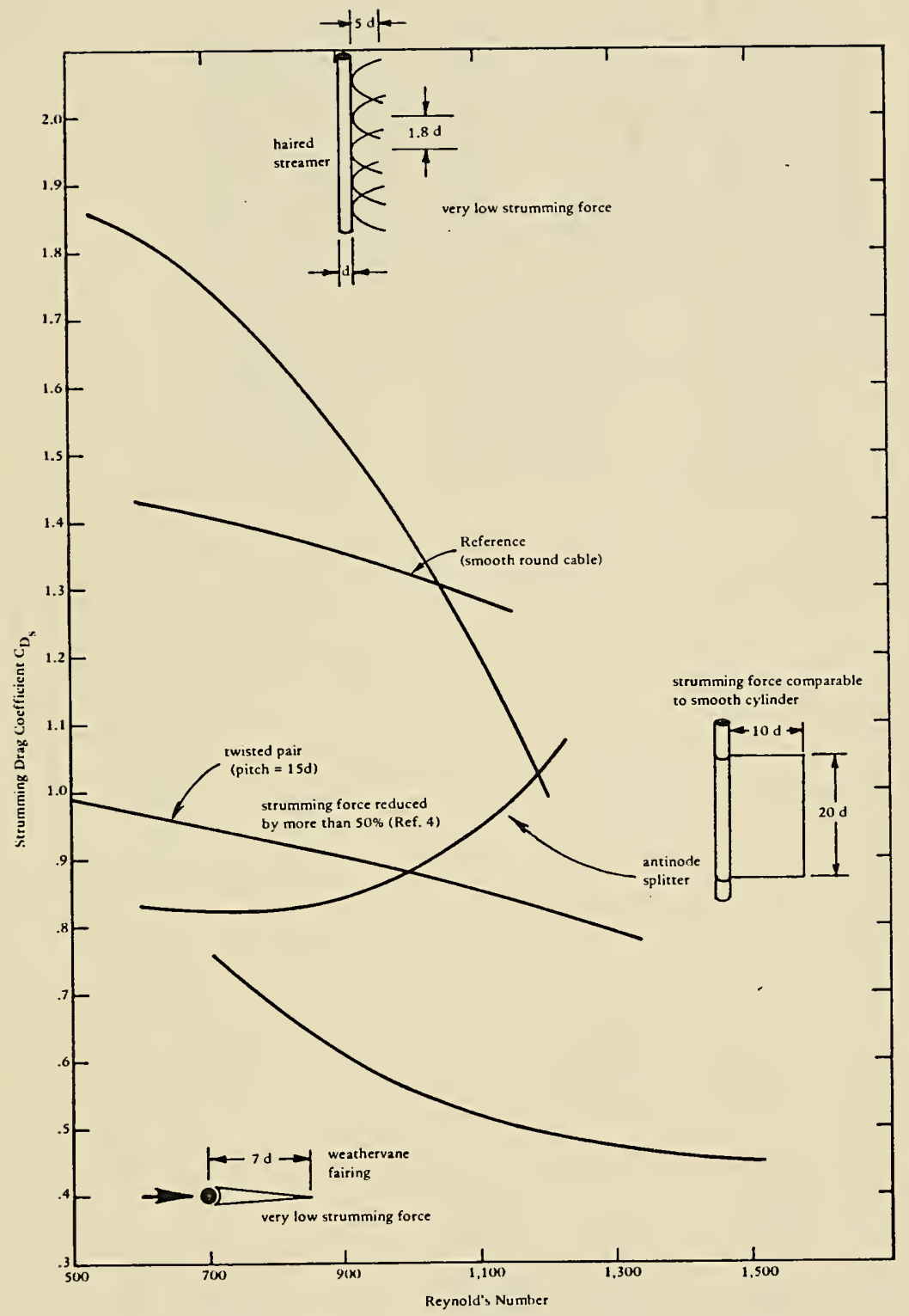

Figure 2. Strumming drag characteristics as found in Reference 106. 



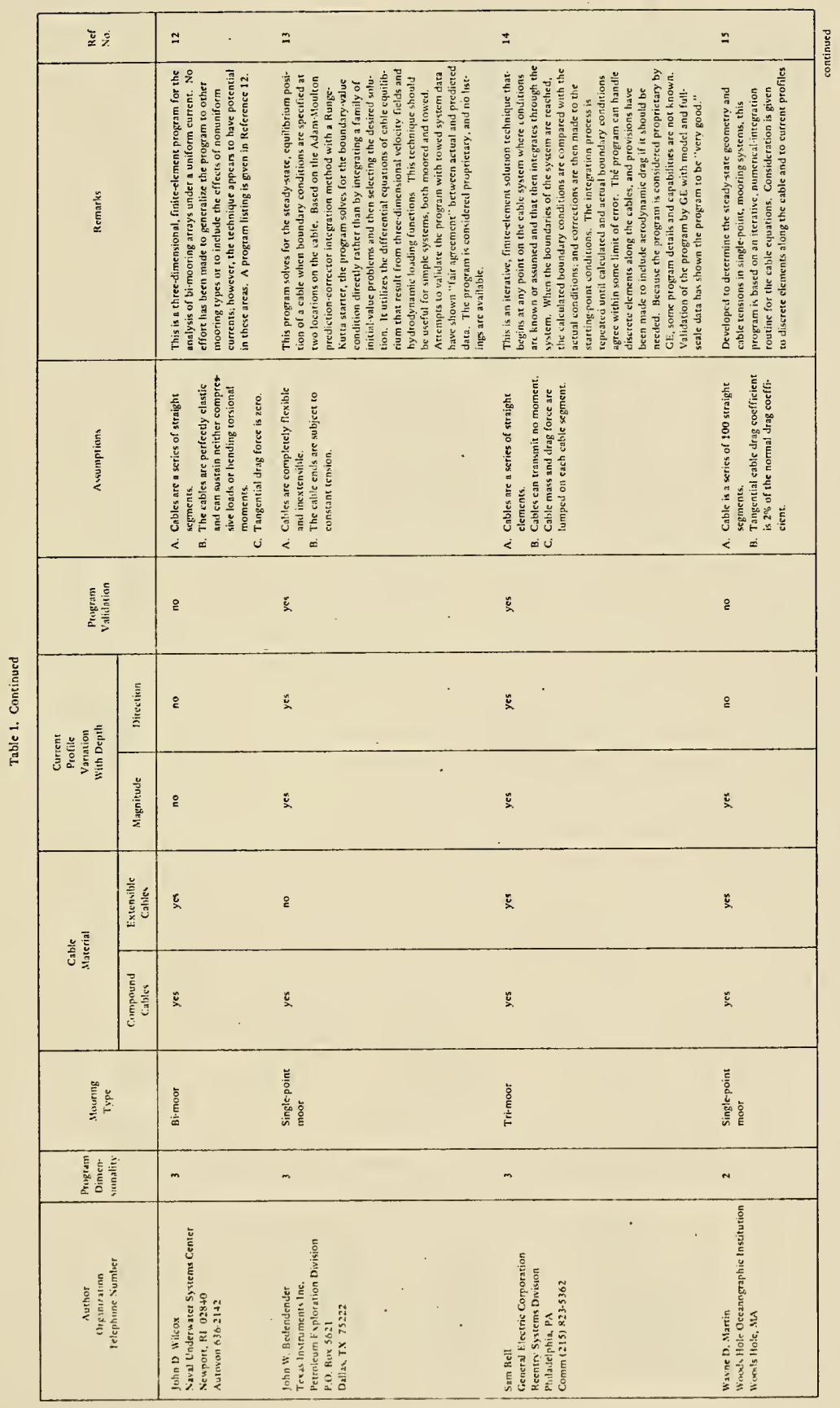





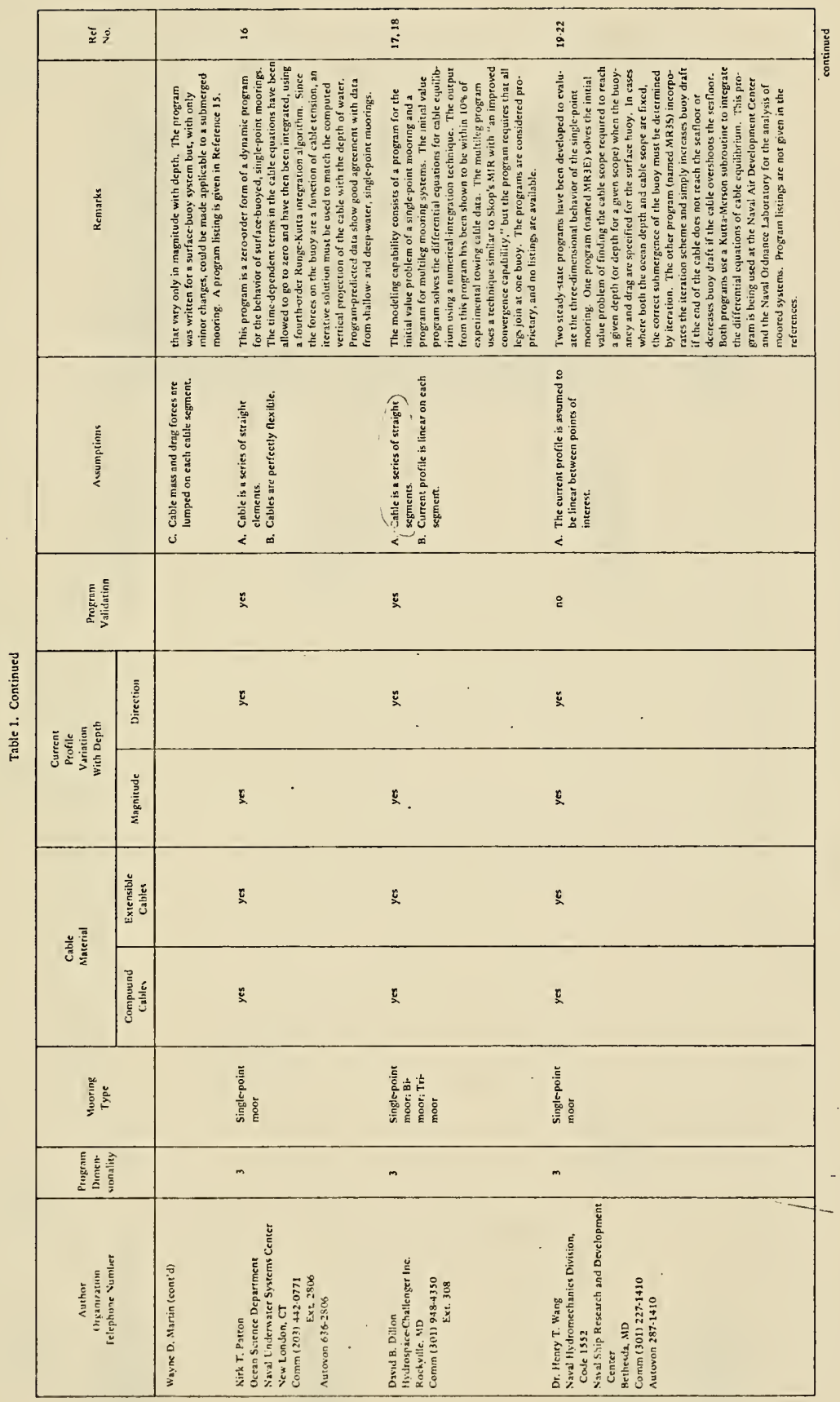





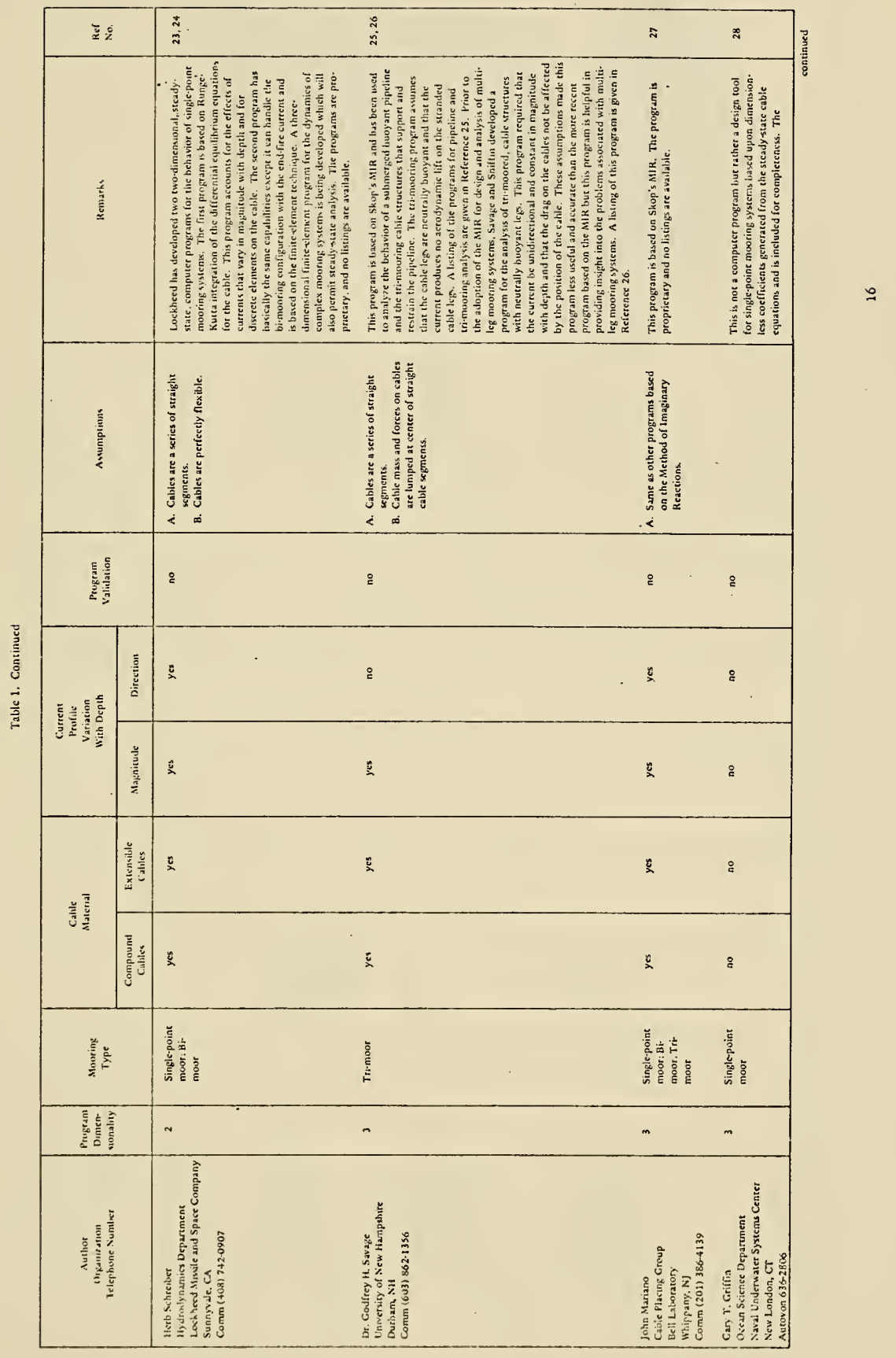





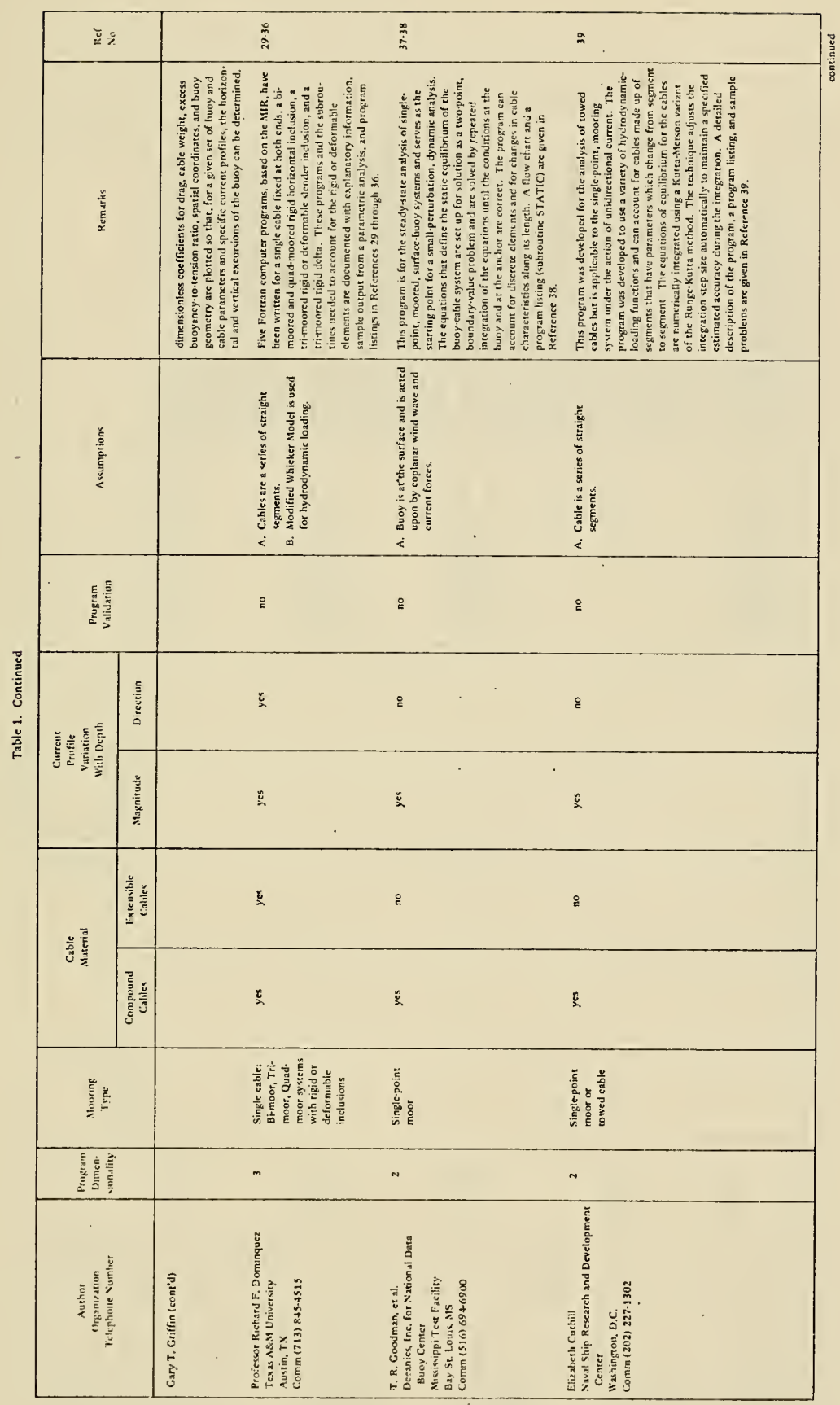

I 



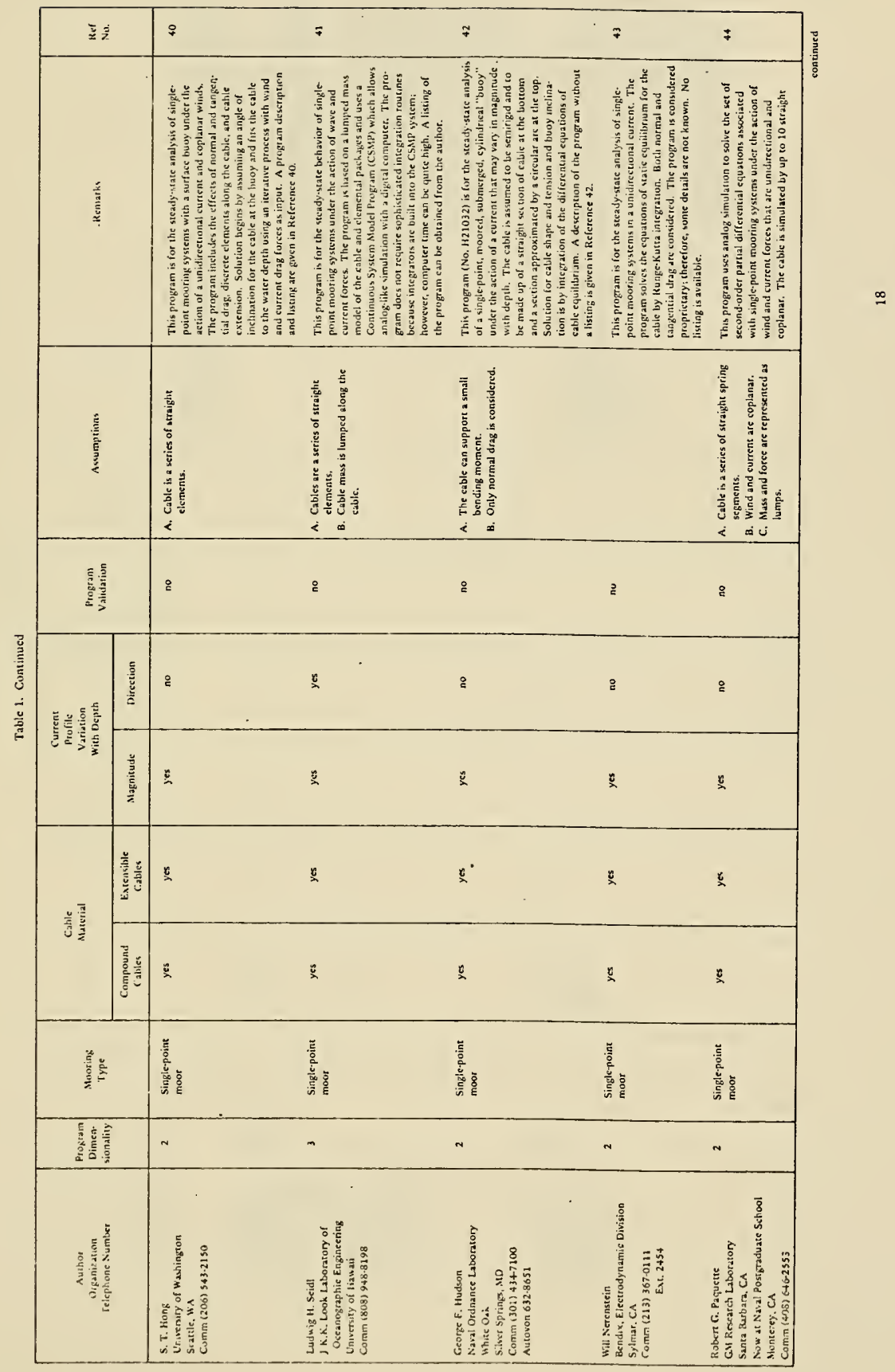





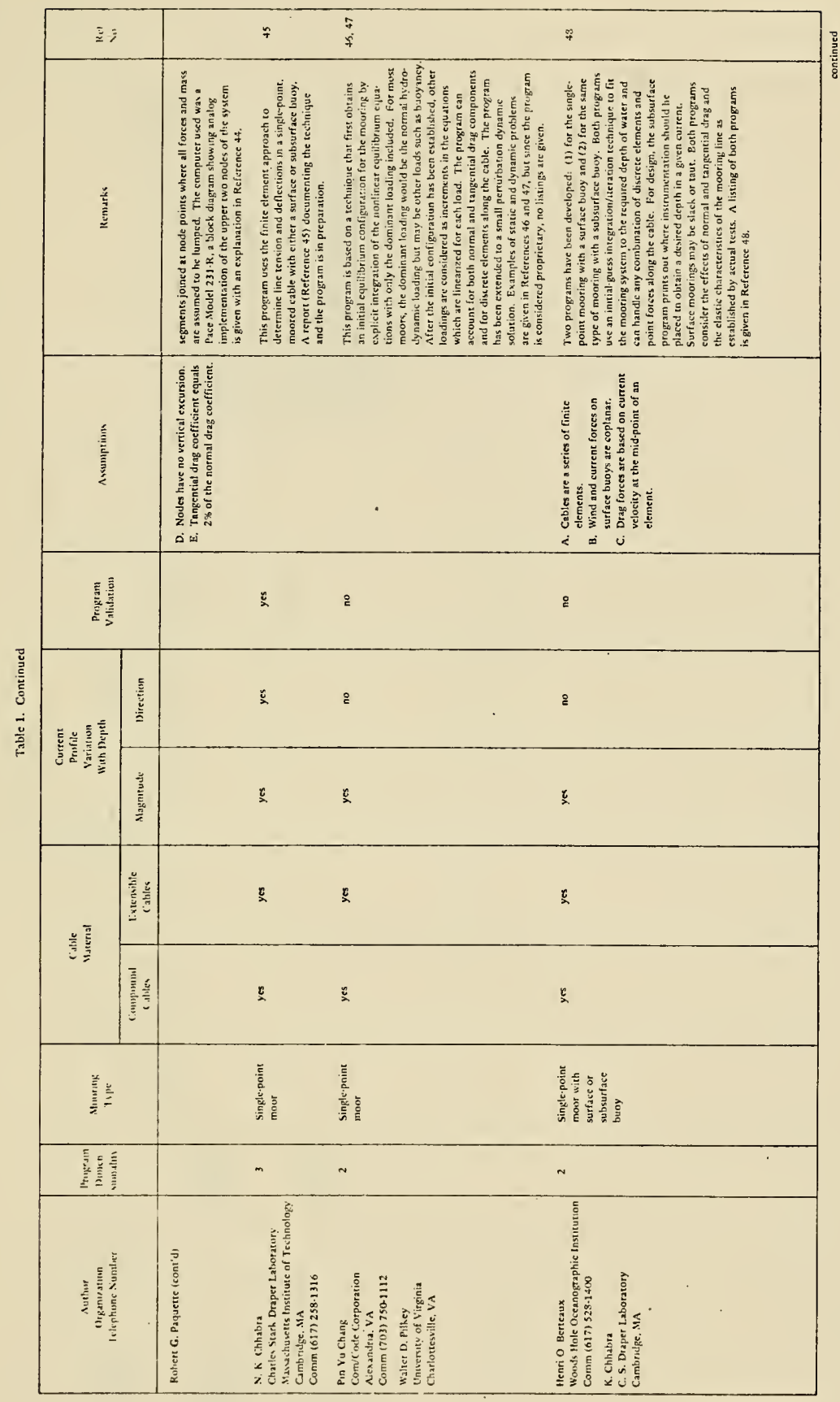





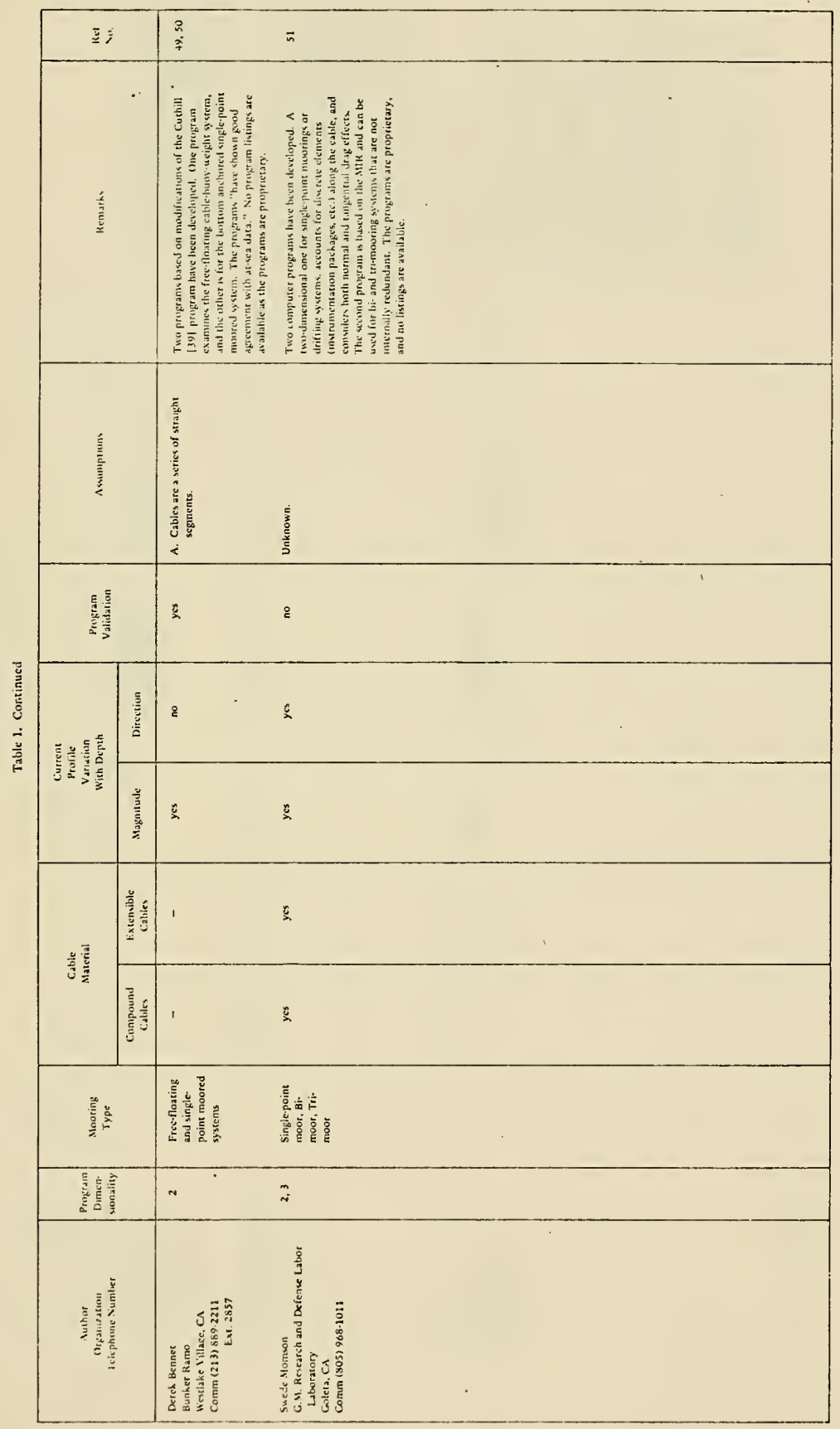





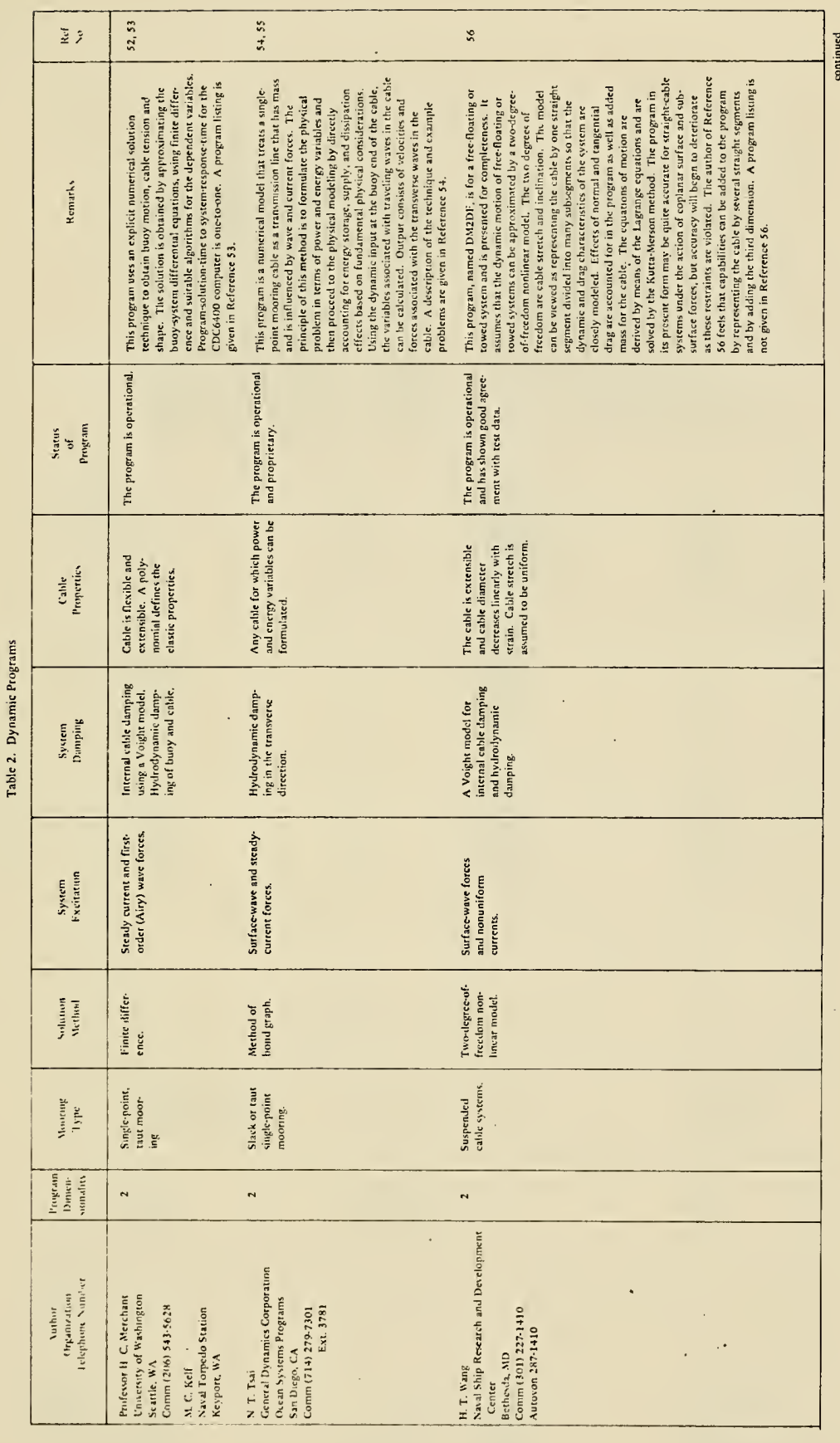





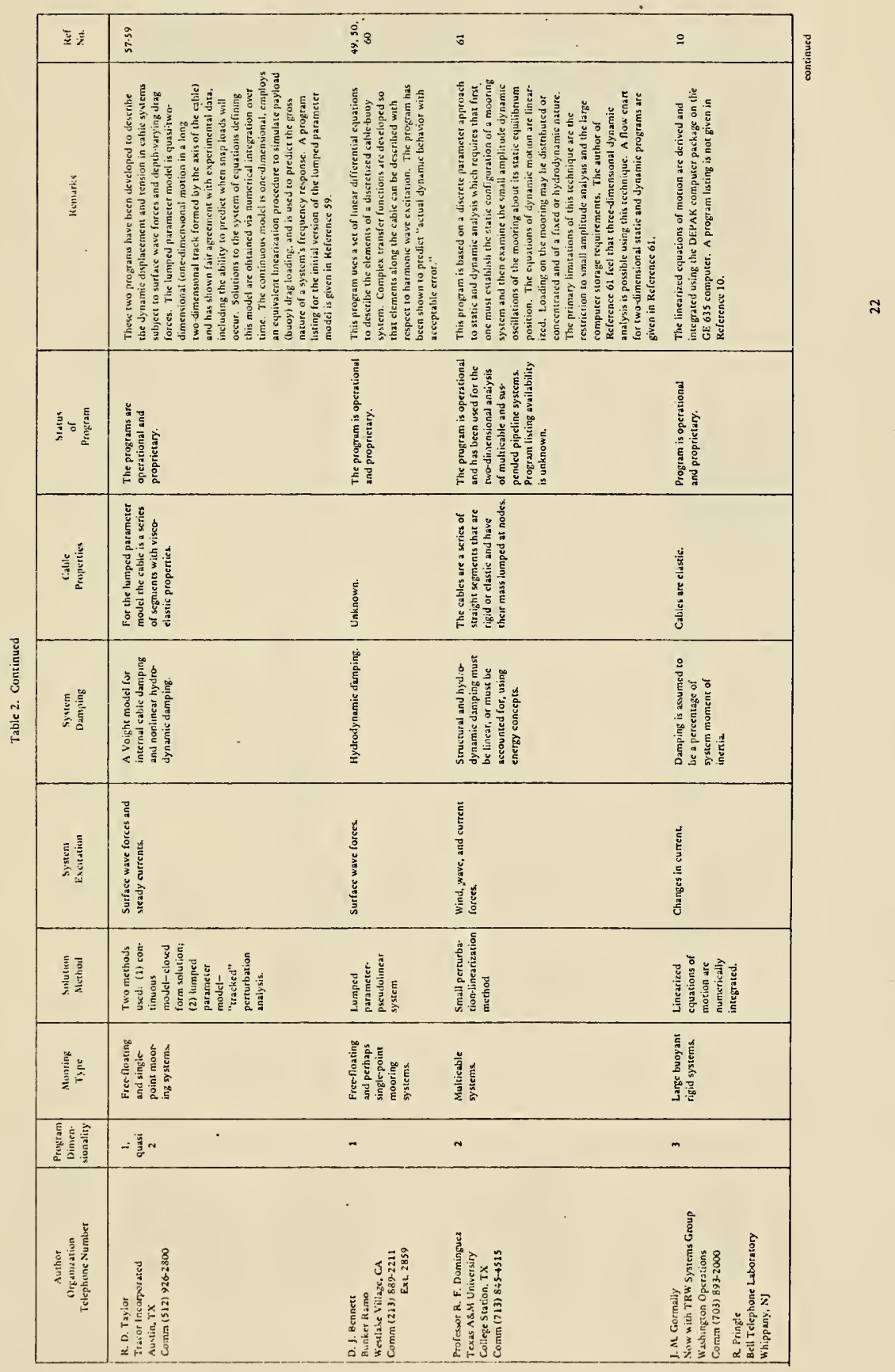





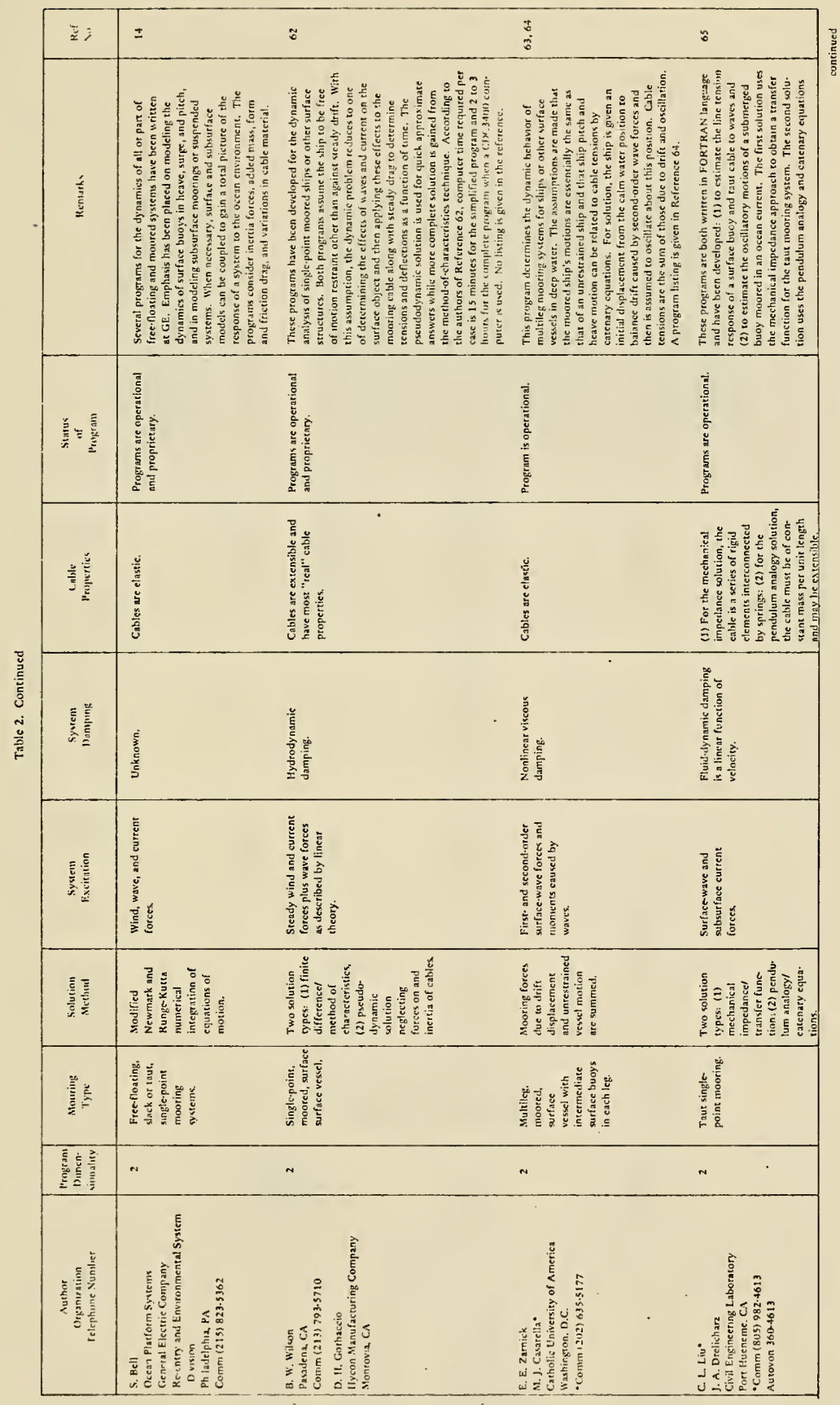




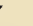




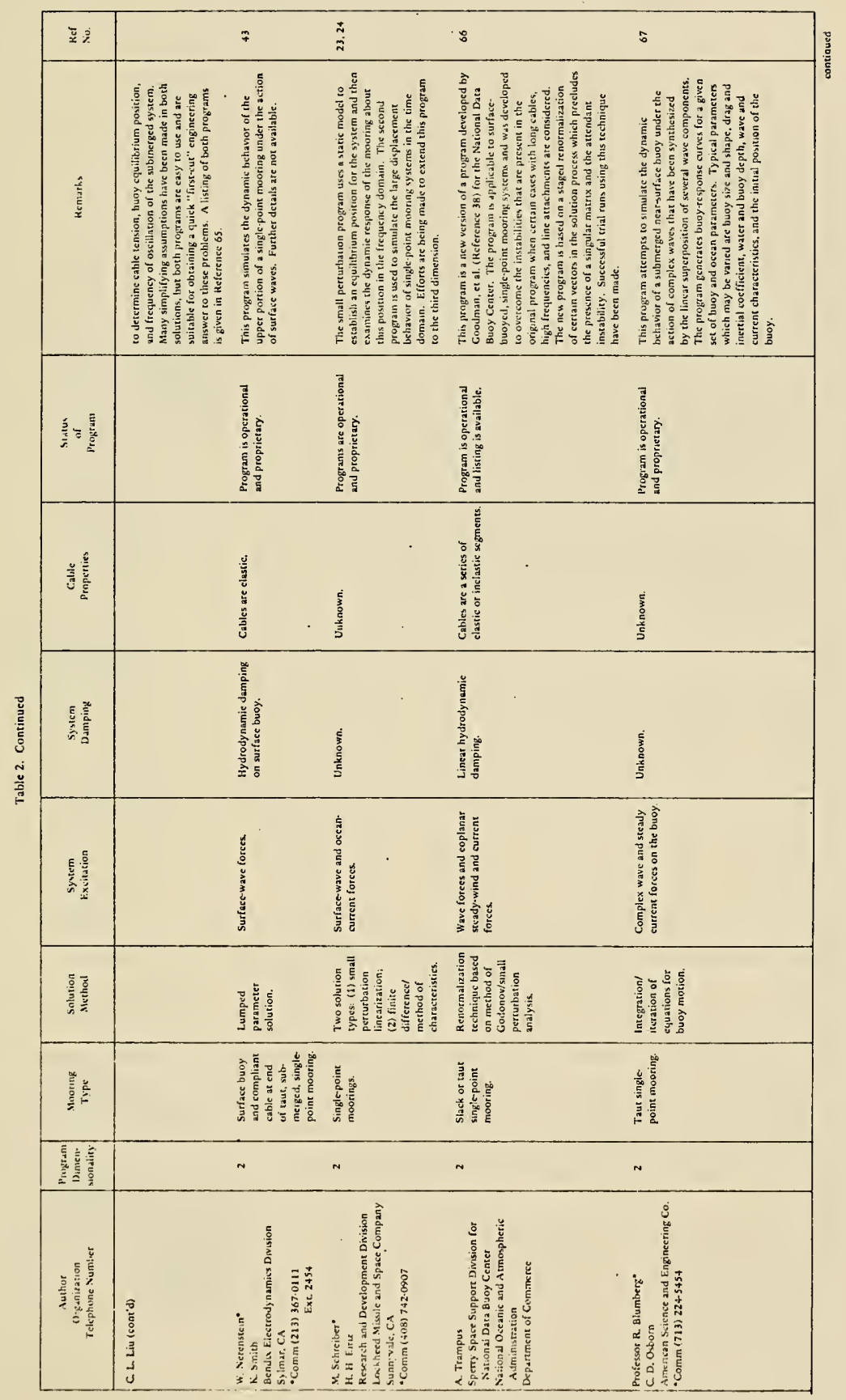





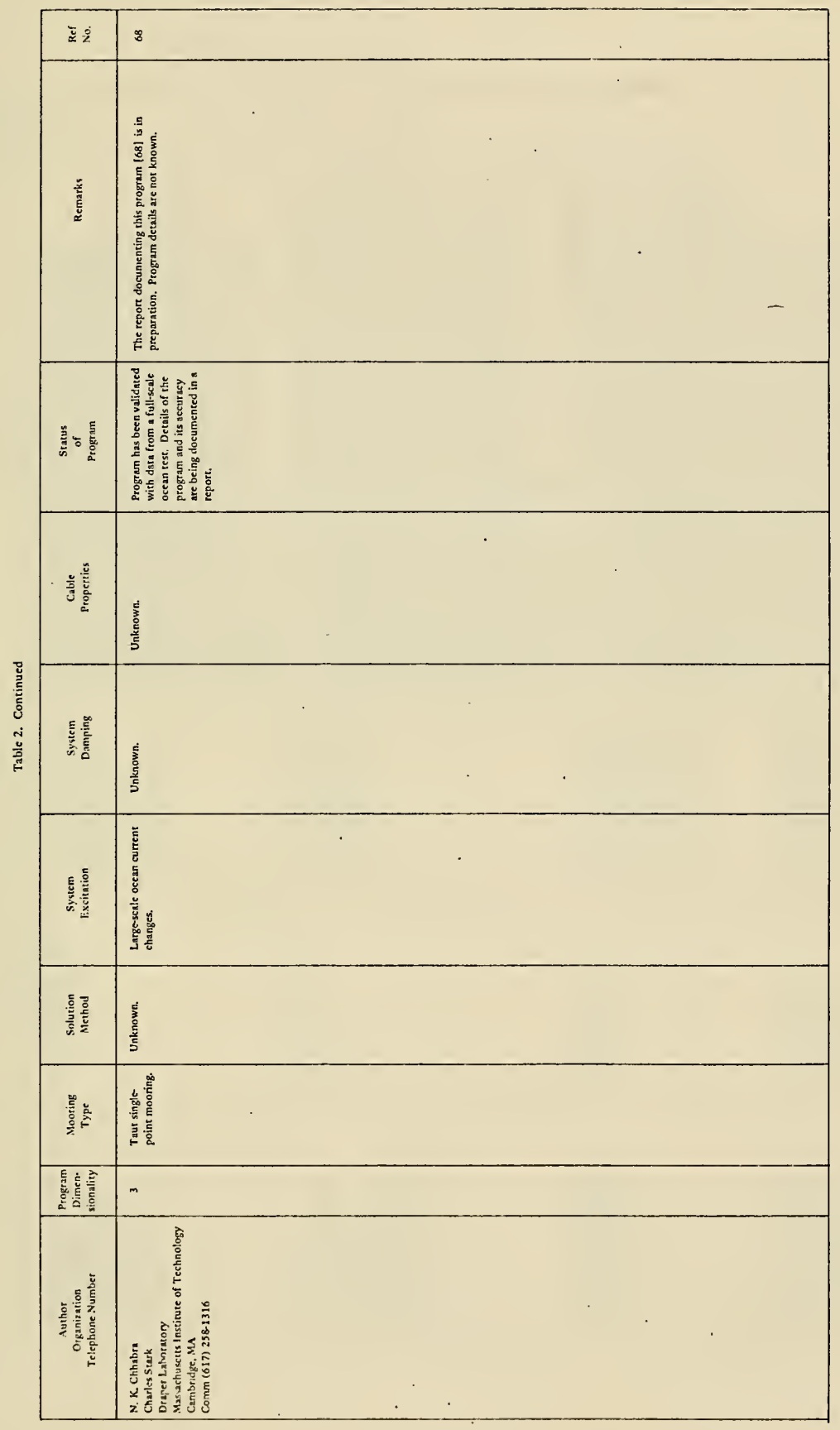





\begin{tabular}{|c|c|c|c|c|}
\hline$\dddot{\dddot{z}} \dot{z}$ & $\stackrel{n}{\stackrel{n}{\sim}}$ & In & $\therefore$ & $\therefore$ \\
\hline 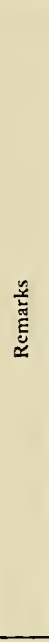 & 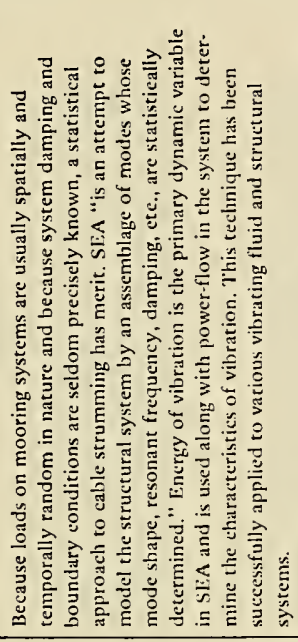 & 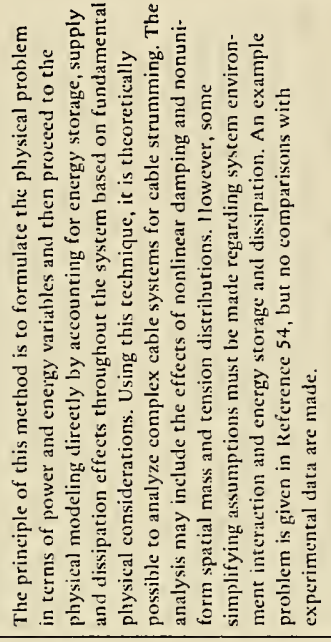 & 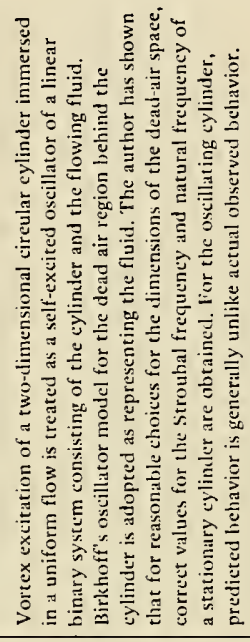 & 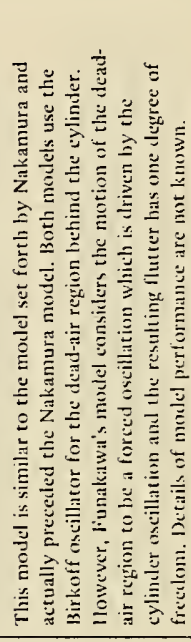 \\
\hline 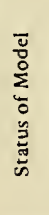 & 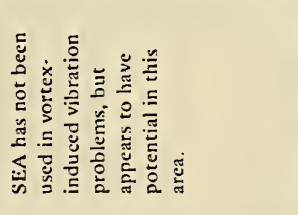 & 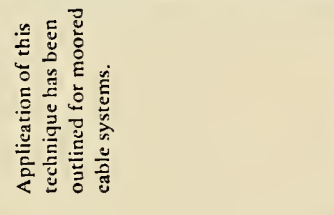 & 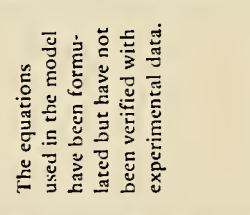 & 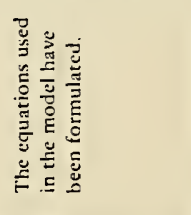 \\
\hline 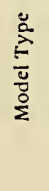 & 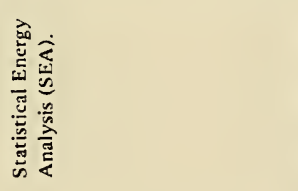 & 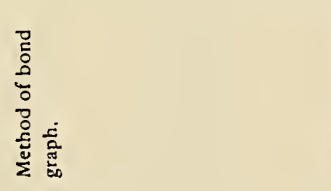 & 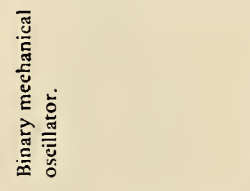 & 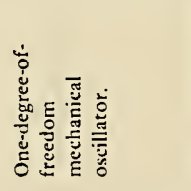 \\
\hline & 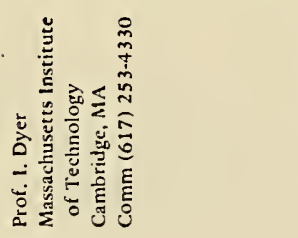 & 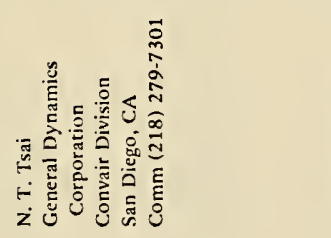 & 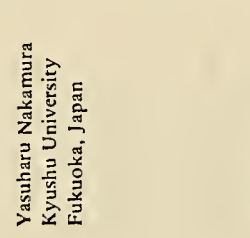 & 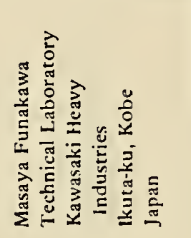 \\
\hline
\end{tabular}




\begin{tabular}{|c|c|c|c|c|c|c|}
\hline$\breve{\check{~}} \dot{z}$ & $\stackrel{x}{*}$ & $\stackrel{2}{R}$ & $\stackrel{\infty}{\infty}$ & $\begin{array}{l}\infty \\
\frac{\infty}{\infty}\end{array}$ & & $\stackrel{m}{\infty}$ \\
\hline 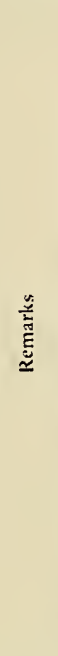 & 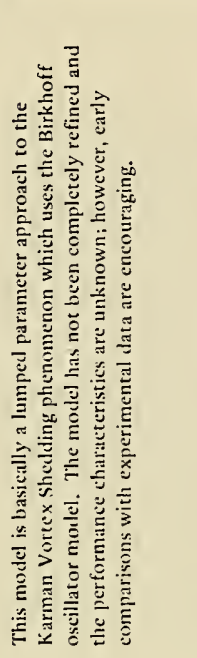 & 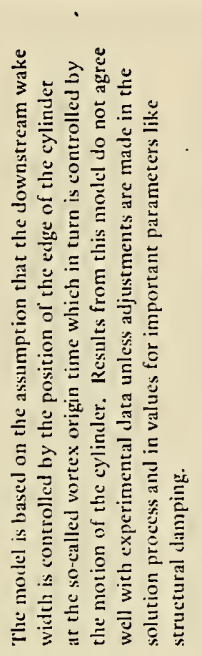 & 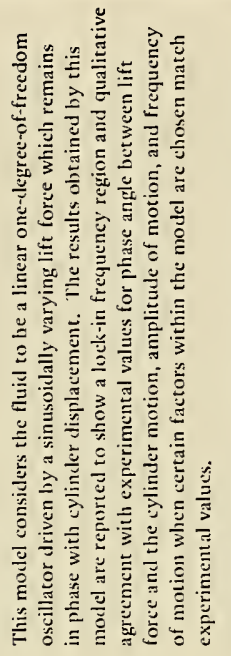 & 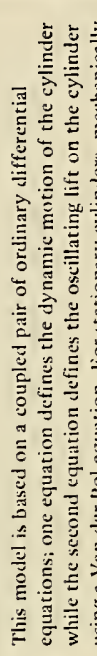 & 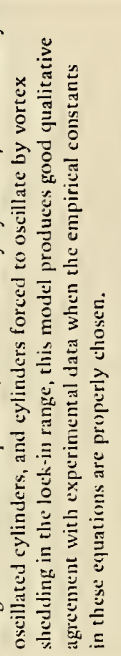 & 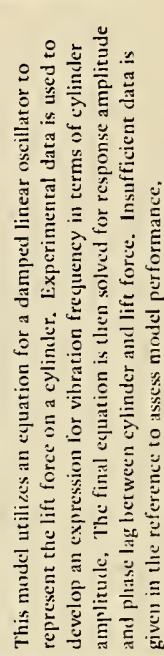 \\
\hline 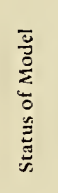 & 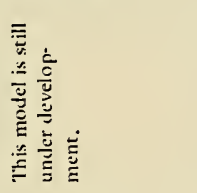 & 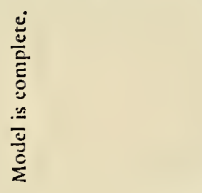 & 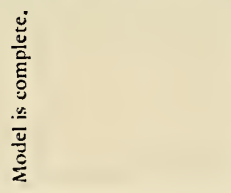 & 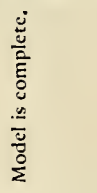 & & 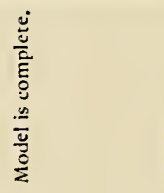 \\
\hline 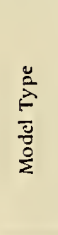 & 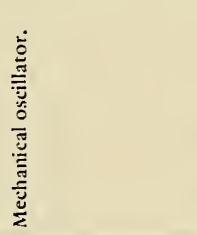 & 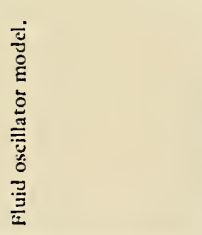 & 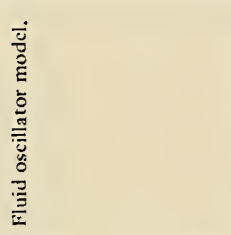 & 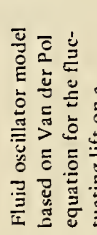 & & 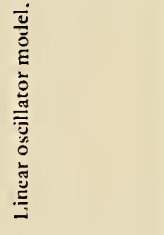 \\
\hline$\stackrel{\stackrel{g}{E}}{E}$ & 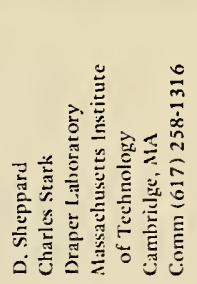 & 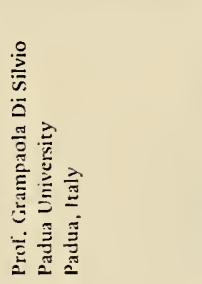 & 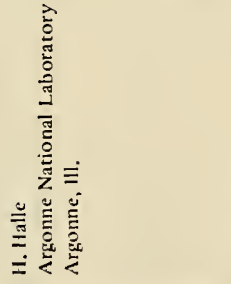 & 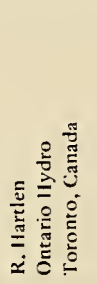 & 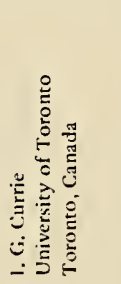 & 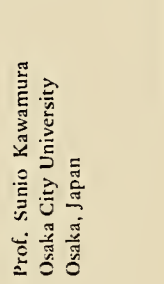 \\
\hline
\end{tabular}






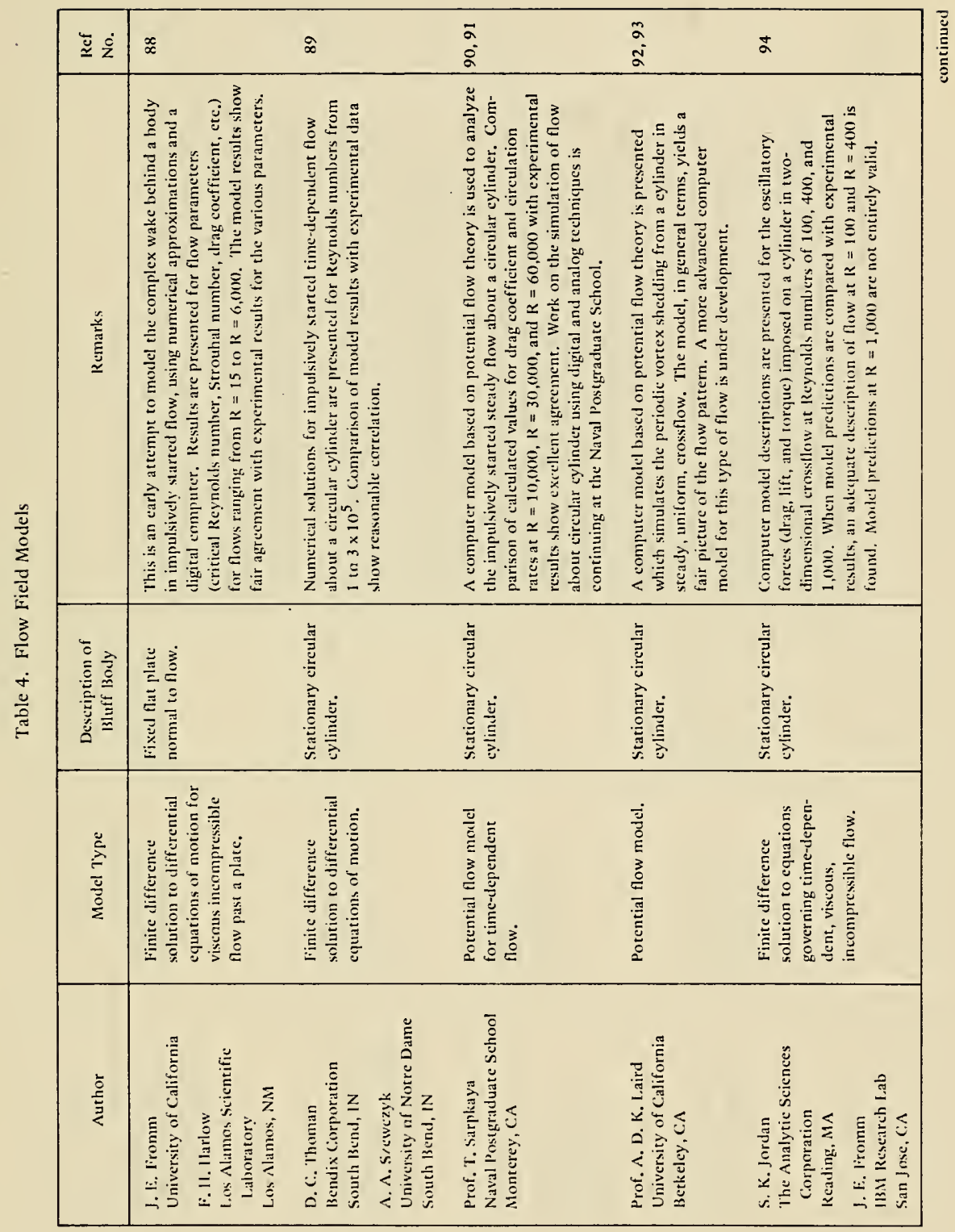





\begin{tabular}{|c|c|c|c|c|}
\hline$\check{\check{z}} \dot{\mathrm{z}}$ & $\approx$ & $\stackrel{0}{2}$ & a & $\begin{array}{l}2 \\
\infty \\
a\end{array}$ \\
\hline 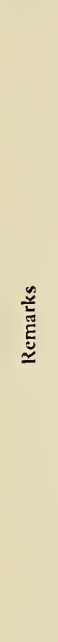 & 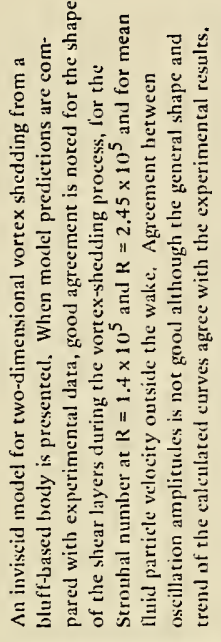 & 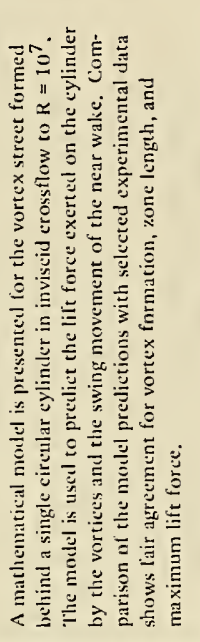 & 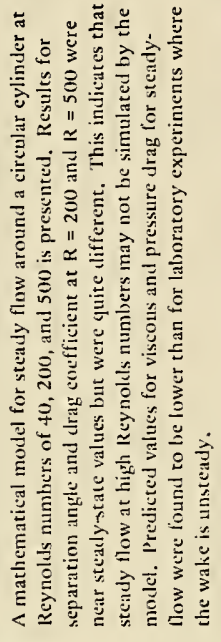 & 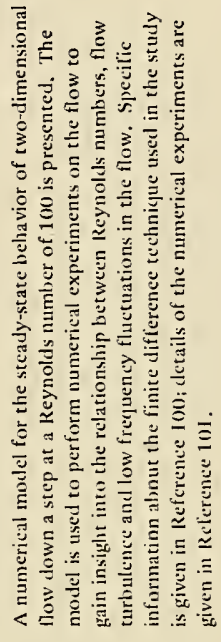 \\
\hline 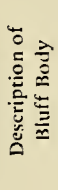 & 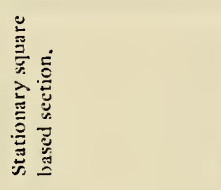 & 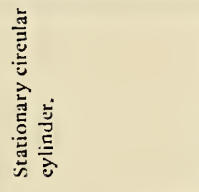 & 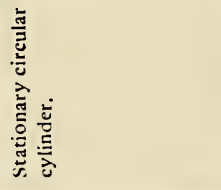 & 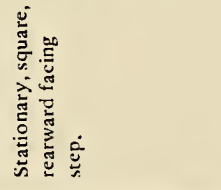 \\
\hline $\begin{array}{l}\frac{\mathrm{o}}{2} \\
\frac{\mathrm{g}}{0} \\
\frac{0}{2}\end{array}$ & 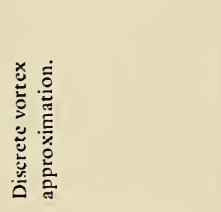 & 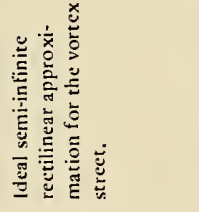 & 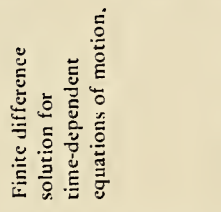 & 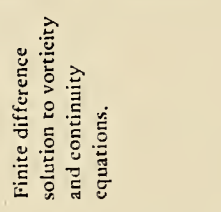 \\
\hline $\begin{array}{l}\stackrel{o}{E} \\
\stackrel{\Xi}{z}\end{array}$ & 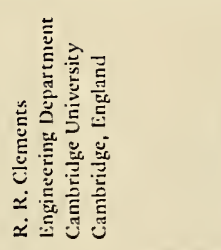 & 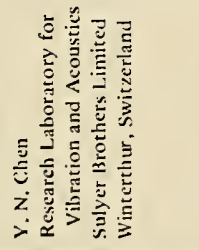 & 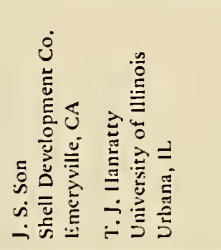 & 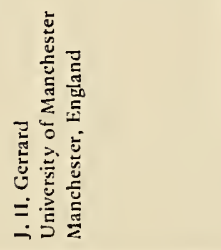 \\
\hline
\end{tabular}





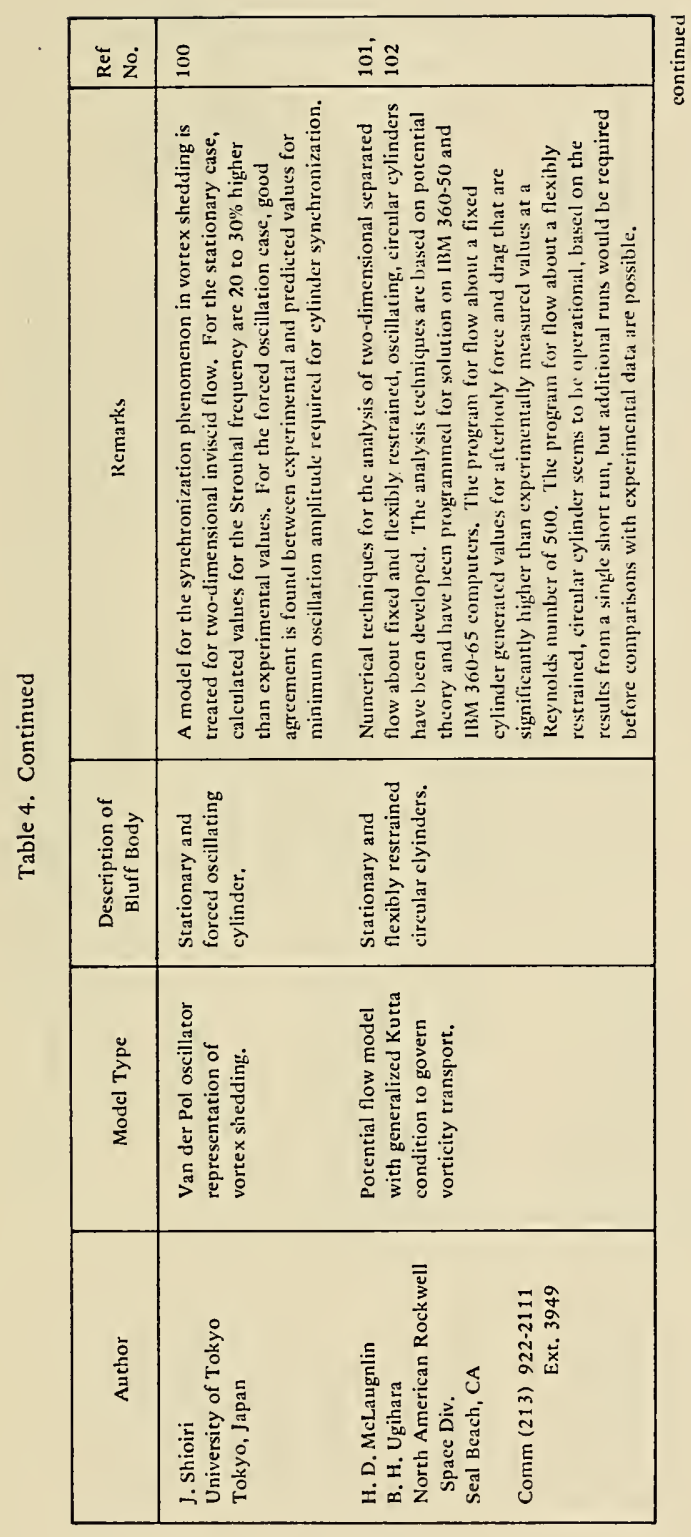





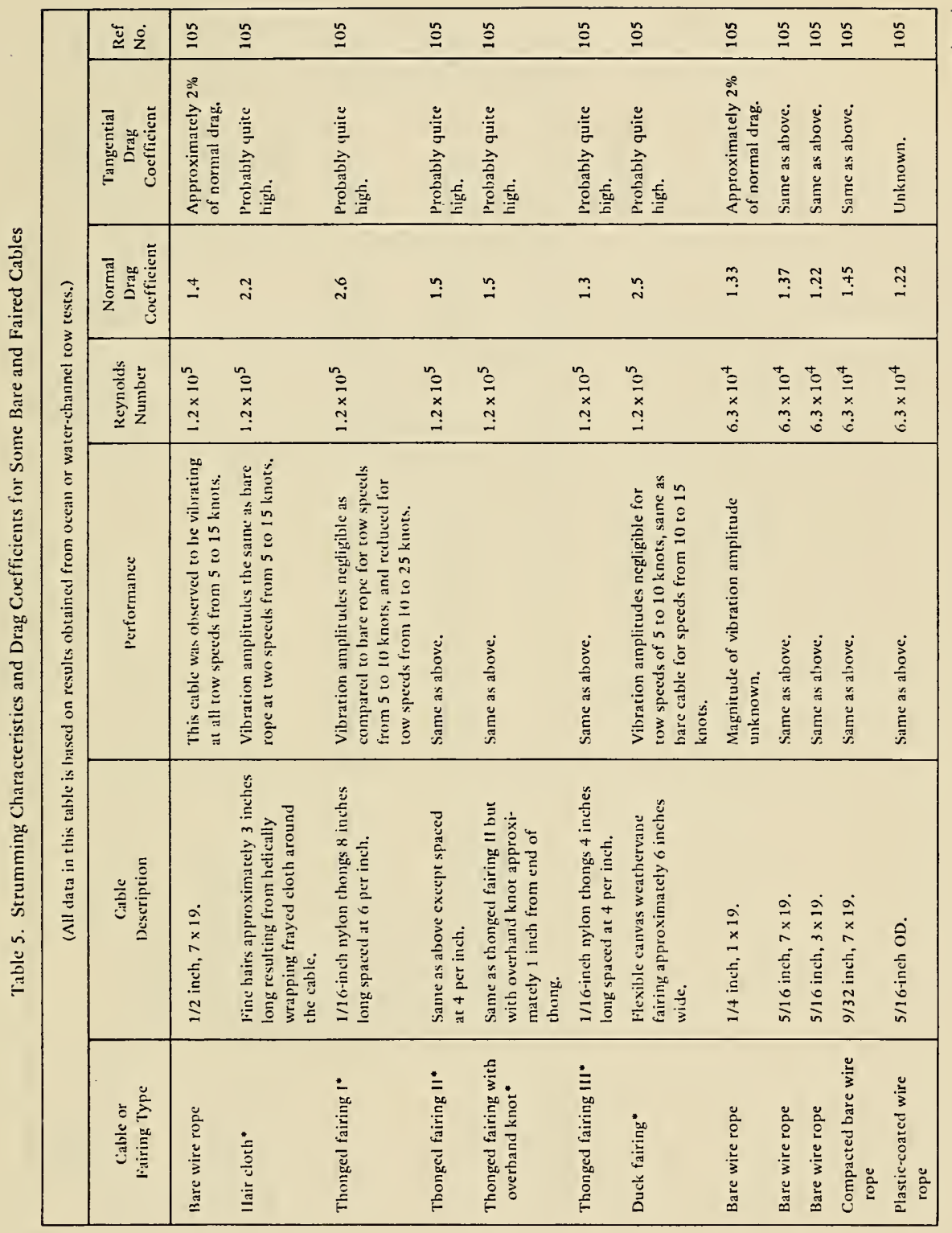





\begin{tabular}{|c|c|c|c|c|c|}
\hline$\ddot{\Xi} \dot{z}$ & $\stackrel{n}{\varrho}$ & $\stackrel{n}{\ominus}$ & $\stackrel{-}{0}$ & 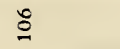 & 今 \\
\hline 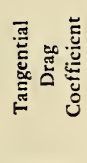 & 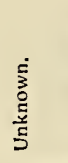 & 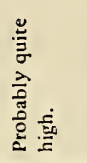 & 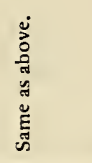 & $\begin{array}{l}\dot{5} \\
3 \\
0 \\
\frac{5}{5} \\
5\end{array}$ & 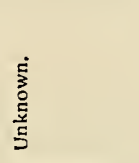 \\
\hline 范 & $\stackrel{\text { 巳 }}{+}$ & $\stackrel{N}{\sim}$ & $\stackrel{t}{I}$ & $\begin{array}{l}5 \\
5 \\
5 \\
5 \\
5 \\
5\end{array}$ & $\begin{array}{l}\dot{1} \\
5 \\
5 \\
5 \\
5 \\
5\end{array}$ \\
\hline 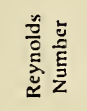 & $\begin{array}{c}+ \\
\stackrel{0}{0} \\
x \\
m \\
0 \\
0\end{array}$ & $\begin{array}{c}\stackrel{+}{0} \\
\stackrel{x}{x} \\
\stackrel{0}{0}\end{array}$ & 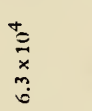 & 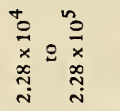 & $\stackrel{\dot{\Phi}}{\stackrel{\infty}{\Xi}}$ \\
\hline 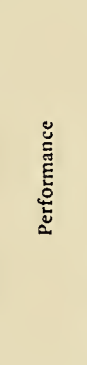 & 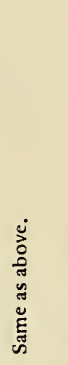 & 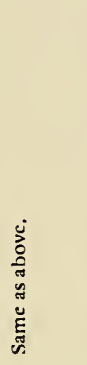 & 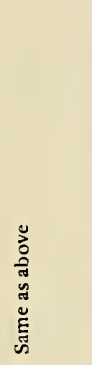 & 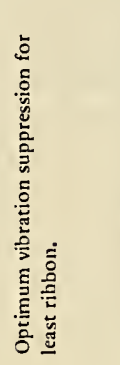 & 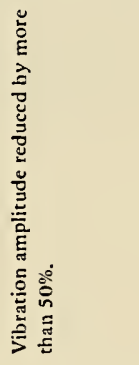 \\
\hline 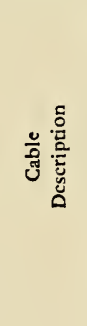 & 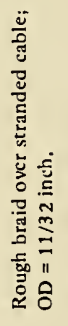 & 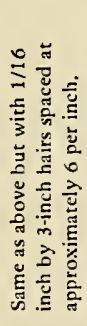 & 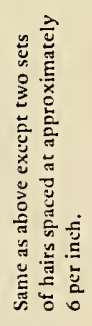 & 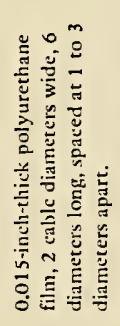 & 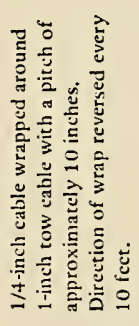 \\
\hline 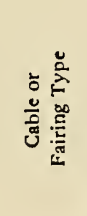 & 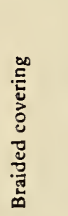 & 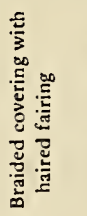 & 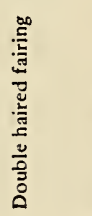 & 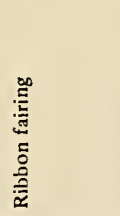 & 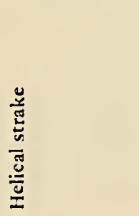 \\
\hline
\end{tabular}



DISTRIBUTION LIST

\begin{tabular}{cccc}
$\begin{array}{c}\text { SNDL } \\
\text { Code }\end{array}$ & $\begin{array}{c}\text { No. of } \\
\text { Activities }\end{array}$ & $\begin{array}{c}\text { Total } \\
\text { Copies }\end{array}$ & \\
- & 1 & 12 & Defense Documentation Center \\
FKAIC & 1 & 10 & Naval Facilities Engineering Command \\
FKNI & 6 & 6 & NAVFAC Engineering Field Divisions \\
FKN5 & 9 & 9 & Public Works Centers \\
FA25 & 1 & 1 & $\begin{array}{l}\text { Public Works Center } \\
\text { RDT\&E Liaison Officers at NAVFAC Engineering Field Divisions } \\
-\end{array}$ \\
\hline & 9 & 9 & $\begin{array}{l}\text { and Construction Battalion Centers } \\
\text { CEL Special Distribution List No. 11 for persons and activities } \\
\text { interested in reports on Ocean Engineering }\end{array}$
\end{tabular}





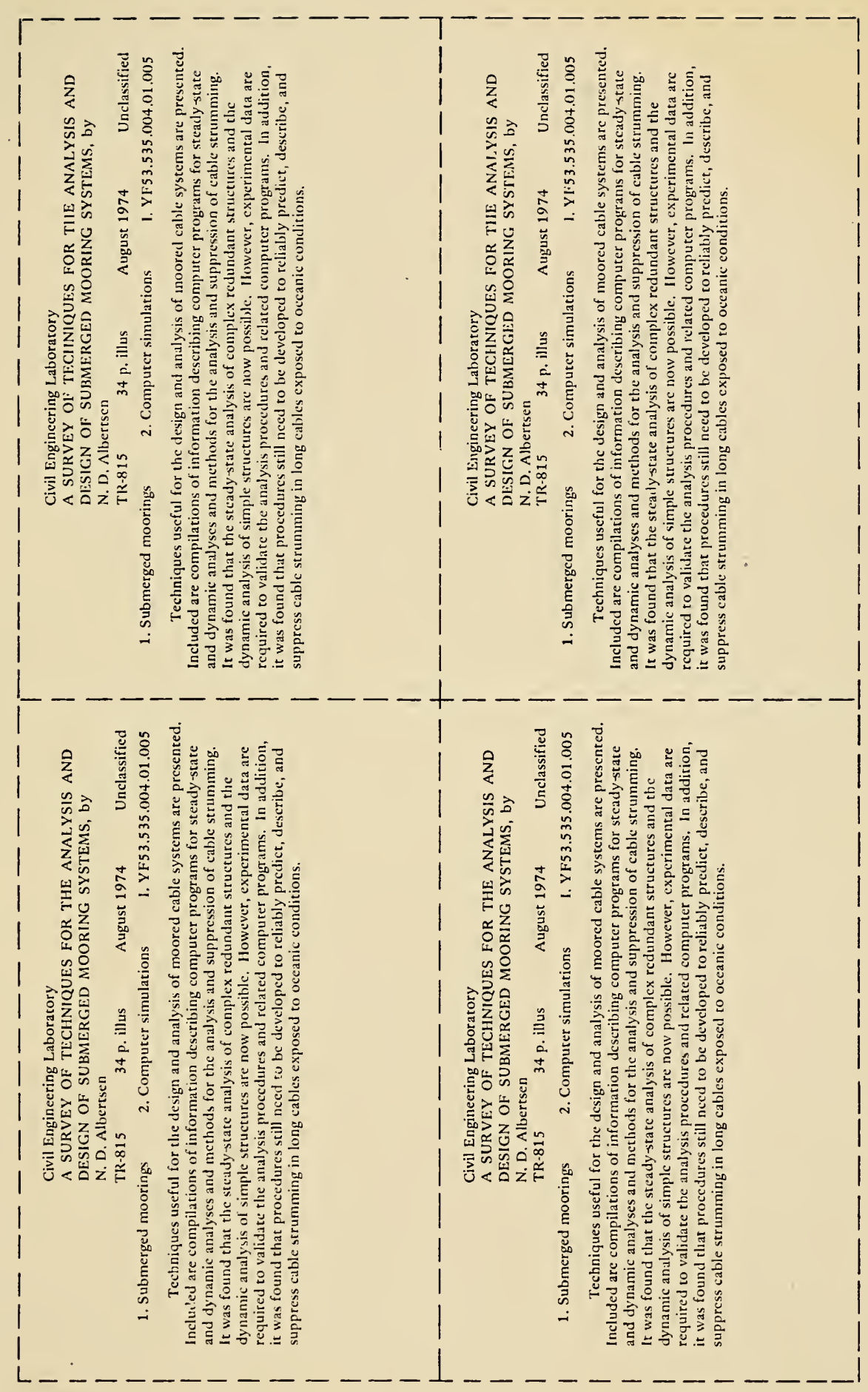


